University of Zurich

Department of Economics

Working Paper Series

ISSN 1664-7041 (print)

ISSN 1664-705X (online)

Working Paper No. 202

\title{
The Welfare Effects of Endogenous Quality Choice in Cable Television Markets
}

Gregory S. Crawford, Oleksandr Shcherbakov and Matthew Shum

August 2015 


\title{
The Welfare Effects of Endogenous Quality Choice in Cable Television Markets*
}

\author{
Gregory S. Crawford \\ Oleksandr Shcherbakov \\ Dept. of Economics \\ Dept. of Economics \\ University of Zurich \\ University of Mannheim \\ Matthew Shum \\ Dept. of Economics \\ California Institute of Technology
}

This draft: August 27, 2015

\begin{abstract}
We measure the welfare consequences of endogenous quality choice in imperfectly competitive markets. We introduce the concept of a "quality markup" and measure the relative importance for welfare of market power over price versus market power over quality. For U.S. cable-television markets between 1997-2006, we find that prices are $33 \%$ to $74 \%$ higher and qualities $23 \%$ to $55 \%$ higher than socially optimal. This "quality inflation" contradicts classic results in the literature and reflects our flexible specification of consumer preferences. Furthermore, we find market power over quality is responsible for $54 \%$ of the total welfare change from endogenous prices and qualities.
\end{abstract}

Keywords: industrial organization, endogenous quality, imperfect competition, monopoly, cable television, quality distortions, welfare, quality markup

JEL Classifications: L15, L13, L82, L96, C51

\section{Introduction}

Market power over price (MPP) is one of the most widely understood and enduring concepts in economics. Whereas competitive markets, under standard assumptions, ensure the maximization

${ }^{*}$ We would like to thank Dan Ackerberg, Gary Biglaiser, Eugenio Miravete, and seminar participants at Arizona, UCLA, Northwestern, Mannheim, Zurich, the University of East Anglia, the CEPR Conference on Competition in the New Economy and the Zhejiang University IO conference for helpful comments. Crawford thanks ESRC Grant RES-062-23-2586 for financial support for this research. Special thanks goes to Chenghuan (Sean) Chu for providing the data used in this analysis and to Ali Yurukoglu, with whom we have had many fruitful discussions about cable television markets. 
of welfare, market power over price creates a wedge between the marginal social benefits and costs of production, introducing inefficiency in the form of deadweight loss. It is not surprising, then, that market power over price is the primary focus of antitrust and competition law and economics. $^{1}$

There is much less focus on concerns about market power over quality (MPQ), or over nonprice attributes more generally. ${ }^{2}$ Just as they do with prices, firms in imperfectly competitive industries will distort quality levels away from socially optimal levels, but unlike prices, the direction of this distortion is not clear. Spence (1975) shows that a single-product monopolist may offer more or less quality than a social planner in the same market, but classic papers in the nonlinear pricing literature argue that multi-product monopolists facing consumers with (restrictive) unidimensional preferences demonstrate incentives to "degrade quality" for its products (Mussa and Rosen (1978), Maskin and Riley (1984)).

In this paper, we measure the welfare effects of endogenous quality choice by U.S. cable television systems. We combine the economic insights of the theoretical literatures described above with the recent empirical literature analyzing demand and pricing in differentiated product markets (Berry (1994), Berry et al. (1995)) to include optimal quality choice. We introduce the concept of a "quality markup" measuring the difference between the marginal social benefit and cost of a change in a product's quality. Much as a price markup is often used as a shorthand measure for the welfare loss from market power over price for the marginal quantity (consumer), a product's quality markup measures the welfare loss associated with market power over quality at the marginal quality. We also measure how much offered qualities differ from those given by a welfare-maximizing social planner, the welfare consequences of these differences, and the relative importance for welfare of market power over price and market power over quality.

Importantly, we find that firms choosing both price and quality in the cable TV market tend to set both prices and quality too high relative to socially optimal levels. This evidence for "quality inflation" is novel compared to the classic results in the theoretical literature discussed above, which predict that a monopolist should engage in quality degradation, and highlights the importance of allowing for flexible consumer preferences in empirical work on these issues.

Our analysis builds on and extends previous empirical research looking at related questions. ${ }^{3}$ Berry and Waldfogel (2001) and Sweeting (2010) empirically analyze the effects of increased market power on product variety and/or quality, but do not optimally solve for those qualities.

\footnotetext{
${ }^{1}$ Examples include price-fixing, predatory pricing, and attempted monopolization, among others (Elhauge (2011)). Similarly, the primary concern of merger review is exercise of market power over price due to unilateral or coordinated action (DOJ and FTC (2010)).

${ }^{2}$ DOJ and FTC (2010, Chap 1) is a notable exception, stating, "Enhanced market power can also be manifested in non-price terms and conditions that adversely affect customers, including reduced product quality, reduced product variety, reduced service, or diminished innovation." They go on to say, "When the Agencies investigate whether a merger may lead to a substantial lessening of non-price competition, they employ an approach analogous to that used to evaluate price competition," but do not provide details.

${ }^{3}$ See Crawford (2012, Section 5) for more details about the related literature.
} 
Clerides (2002) and Verboven (2002) analyze quality-based price discrimination, but focus primarily on documenting its presence. Where the types of products a firm can offer are discrete, the choice facing firms is whether or not to add any such product. In this vein, Draganska et al. (2009), Eizenberg (2014), Nosko (2014), and Sweeting (2013) recover the fixed costs of offering new products and, in some cases, endogenously solve for new product introductions. Gandhi et al. (2008), Chu (2010), Fan (2013), and Byrne (2011) study firms' endogenous choices of continuous characteristics while holding the set of products fixed, as in this paper. Finally, we contribute to the literature analyzing economic issues in pay television markets (Goolsbee and Petrin (2004), Crawford and Yurukoglu (2012), Crawford et al. (2015)).

The papers closest in spirit to ours are McManus (2007) and Crawford and Shum (2007). Both find evidence of quality degradation for low-quality products along the lines predicted by the theoretical literature above. Here, in contrast, using more flexible specification of preferences, we find evidence of quality inflation, even for low-quality products. Furthermore, our empirical framework allows us to go further to compare the welfare implications of firms' price vs. quality distortions. These are novel contributions to the literature.

The empirical framework we propose is based closely on the empirical analysis of differentiated product markets pioneered by Berry (1994) and Berry et al. (1995). ${ }^{4}$ On the demand side, we specify a Random Coefficient Logit (RCL) model with random coefficients on price and quality. We specify a total cost function which depends on both quantity and quality. Cable systems maximize profits by choosing optimally the price and quality of the number of products they choose to offer, which we take as given. ${ }^{5}$ Estimation is by GMM using moments generated by demand and the first-order conditions for prices and qualities. Demand, marginal (quantity) cost and marginal quality cost shifters serve as instruments. ${ }^{6}$

We estimate the model on a dataset of almost 12,000 cable system years between 1997 and 2006. We also incorporate annual data on prices and quality for satellite competitors over the same period. U.S. cable television markets during our sample period are well suited for our model for three reasons. First, the products cable systems offer are bundles of television networks with higher-quality bundles uniformly including all of the networks in lower quality bundles (and more). Limiting an empirical analysis to a single dimension of product quality is therefore reasonable in this setting. Second, there is interesting variation in the competition faced by systems in the sample. In the early part of our sample, cable television systems are

\footnotetext{
${ }^{4}$ Applications using this framework are too numerous to count but include measuring the market power of firms (Nevo (2001)), conducting simulations of potential mergers (Berry and Pakes (1993)), testing for price discrimination (Verboven (2002)), and quantifying the welfare benefits of new goods (Petrin (2002)).

${ }^{5}$ The number of offered products depends on the technology used by cable systems and is therefore plausibly exogenous to annual price and quality decisions.

${ }^{6}$ Our framework also addresses the endogeneity of quality in the estimation of demand, an important econometric problem in its own right. Relatedly, see Ackerberg et al. (2011) for methods to consistently estimate (only) price elasticities in the presence of endogenous product characteristics, which can be multidimensional (unlike the case of scalar quality considered here).
} 
largely local monopolies; while satellite competitors entered in the mid-1990s, regulations on their ability to import local broadcast networks before 2000 limited their ability to compete with incumbent cable systems. ${ }^{7}$ Finally, our data on cable (and satellite) markets are rich enough to accurately analyze endogenous quality. Cable systems in our data serve geographically distinct local cable markets. Within the sample, each offers at most 3 bundles of networks. For each offered bundle, we observe the price charged, its market share, and the television networks it offers. Following previous work in this literature (Chu (2010), Shcherbakov (2012)), we use a weighted total number of television networks in a bundle as our measure of quality for that bundle, with weights for each channel given by the national average input costs paid by cable systems for that channel. ${ }^{8}$ We also observe (at the market level) variables that shift demand and costs across markets.

Based on our estimates of preferences and costs, we calculate price and quality markups along the lines described above. We also measure consumer surplus, profit, and thus total surplus associated with observed prices and qualities. We then simulate counterfactual prices and qualities for a social planner offering the same number of products and maximizing total surplus in each market. We compare the qualities offered in the market with those offered by a social planner, the difference in consumer and total surplus between what the monopolist and social planner would offer, and the relative share of this total due to market power over price versus market power over quality.

Our results show that market power over quality has an important impact on consumer welfare in ways not previously demonstrated in either the theoretical or empirical literatures. From a social welfare perspective, we first find that both prices and qualities are too high: across the types of products offered by the firms in our sample, we find average estimated price markups range from $17 \%$ to $34 \%$ percent and average estimated quality markups between $0 \%$ and $43 \%$. Keeping prices fixed at observed levels, we show that firms would degrade quality: offered qualities are between $7 \%$ and $58 \%$ lower than efficient qualities, with the largest effects arising for one-good markets and low-quality goods in two- and three-good markets.

Allowing for efficient prices and qualities, however, shows both are too high: we estimate the social planner would lower qualities by between $23 \%$ and $55 \%$ (and prices by between $33 \%$ and $74 \%$ ). This evidence for "quality inflation" by cable operators reverses previous theoretical and empirical results (Mussa and Rosen (1978), Crawford and Shum (2007)) which predict that a monopolist should engage in quality distortion, and highlights the necessity of allowing for flexible and rich specifications of consumer preferences in empirical work on these questions.

\footnotetext{
${ }^{7}$ Furthermore, while cable system prices were regulated in 1992, the effects of these regulations were mitigated due to the nature of their implementation and were effectively withdrawn for the vast majority of cable bundles by 1996. See Crawford and Shum (2007) for more detail on the regulations and the effects they had on cable market quality.

${ }^{8}$ Thus channels that are expensive to the cable system (ESPN, TNT, CNN, etc.) contribute more to the measured quality of a cable bundle than channels that are inexpensive to the system.
} 
It opens an important insight into how consumers trade off price versus quality and may be particularly relevant to US policymakers concerned about high and rising pay television prices.

Finally, we measure the relative importance of market power over price versus market power over quality and find that they are roughly comparable, with the former (latter) accounting for an estimated $46 \%$ (54\%) of the total surplus change between observed and efficient prices and qualities. ${ }^{9}$

The rest of the paper proceeds as follows. In the next section we describe the economic intuition underlying the measurement of market power over quality. In Section 3 we describe the institutional features of U.S. cable television markets that make estimating the model there attractive as well as the data we are using for our analysis. We also describe there the data we will use for our analysis. In Section 4 we describe the equilibrium demand and supply framework underlying our empirical model. In Section 5 we elaborate on details of model specification, and discuss the identification of structural parameters and our choice of instrumental variables for estimation. Section 6 presents our estimation results, and also the results from counterfactual experiments which compare the observed prices and qualities to socially optimal values. Section 7 concludes.

\section{Market power over quality}

In this section we describe the economic intuition underlying our measurement of market power over quality. Following Spence (1975) and Mussa and Rosen (1978), respectively, we compare a monopolist's choice of product quality to what a social planner would choose. We introduce a measure of quality markups and describe how we measure the absolute and relative welfare effects of market power over price versus market power over quality.

Following Spence (1975), we begin with the simplest case where a single product monopolist chooses quality, $q$, and price, $P$. For simplicity, assume that each consumer buys one unit of the good. Let $P(s, q)$ denote the inverse demand function facing the monopolist, where $s$ denotes quantity, and let $C(s, q)=c(q) s$ be a constant returns to scale cost function. The monopolist's first order conditions for quantity and quality controls are then

$$
\begin{aligned}
& \text { F.O.C. }{ }^{M}[s]: P(s, q)+P_{s}(s, q)=c(q), \\
& \text { F.O.C. }{ }^{M}[q]: P_{q}(s, q)=c_{q}(q),
\end{aligned}
$$

where $P_{q}(s, q)$ is Spence's "marginal valuation of quality" $(M V Q)$ for the $s^{\text {th }}$ consumer. ${ }^{10}$

\footnotetext{
${ }^{9}$ Consistent with our earlier results on quality markets, the relative importance of market power over price versus quality varies across market types, with market power over quality accounting for $74 \%$ of the total welfare effect in one-good markets, but only $19 \%$ and $40 \%$ in two- and three-good markets.

${ }^{10}$ If $P(s, q)$ measures the willingness-to-pay of the $s^{t h}$ consumer, then $P_{q}(s, q)$ measures how much her WTP increases with increases in quality.
} 
A social planner maximizes total surplus

$$
\max _{s, q}\left\{\int_{0}^{s} P\left(s^{\prime}, q\right) d s^{\prime}-c(q) s\right\}
$$

yielding first order conditions for quantity and quality that equate the marginal social benefit of each with their marginal cost,

$$
\begin{aligned}
& \text { F.O.C. }{ }^{S P}[s]: P(s, q)=c(q), \\
& \text { F.O.C. }{ }^{S P}[q]: \frac{1}{s} \int_{0}^{s} P_{q}\left(s^{\prime}, q\right) d s^{\prime}=c_{q}(q) .
\end{aligned}
$$

While the difference between (1) and (3) is familiar as a manifestation of market power over price, the difference between (2) and (4) shows that profit maximizing and socially optimal quality levels are also likely to be different. While the monopolist equates the marginal quality cost, $c_{q}(q)$, to the marginal value of quality for the marginal $\left(\mathrm{s}^{\text {th }}\right)$ consumer, $P_{q}(s, q)$, the social planner equates it to the marginal value of quality to the marginal value of quality, averaged across all consumers, $\frac{1}{s} \int_{0}^{s} P_{q}\left(s^{\prime}, q\right) d s^{\prime}$.

As Spence shows, which of the two chooses the larger quality depends on (1) how the marginal value of quality, $P_{q}(s, q)$, varies with $s$, i.e., whether high- or low-willingness-to-pay consumers value more increases in quality, and (2) the extent of quantity reduction under monopoly (as that affects both who is the monopolist's marginal consumer as well as the set of consumers over which the social planner averages). Figure 1 demonstrates this effect in a simple Logit specification, where $\gamma$ is the coefficient on a price-quality interaction term. ${ }^{11}$ Positive values for $\gamma$ imply that increments to quality make the demand curve progressively steeper. In this case, described in the left panel of Figure 1, the marginal valuation of quality increases more for high-willingnessto-pay consumers, the monopolist restricts quantities considerably and over-provides quality. ${ }^{12}$ In the second panel, the marginal valuation of quality increases more for low-willingness-to-pay consumers and the monopolist still restricts quantities, but now under-provides quality. ${ }^{13}$ Which of the two occurs in practice is, of course, an empirical question which we address for US cable television markets in this paper.

Models of multi-product monopoly quality choice typically apply principal-agent models of adverse selection like those used in the analysis of optimal nonlinear pricing. The seminal papers in this area are Mussa and Rosen (1978) and Rochet and Stole (2002). Under standard assumptions, a common set of results emerge: (1) quality to the highest type is set efficiently (i.e. there

\footnotetext{
11 i.e., $\log \left(s_{j} / s_{0}\right)=\alpha_{0}+\alpha_{p} p_{j}+\alpha_{q} q_{j}+\gamma p_{j} q_{j}+\xi_{j}$.

${ }^{12}$ Essentially, $P_{q}$ at $s^{M}=0.328$ is greater than the average $P_{q}$ between 0 and $s^{S P}=0.685$.

${ }^{13}$ For a Logit model with $\gamma=0$ there is no heterogeneity across consumers in marginal valuation of quality. As a result, the willingness-to-pay increase of the monopolist's marginal consumer is identical to that of the social planner's average consumer and they both choose the same (efficient) quality. One should therefore be careful accommodating endogenous quality choice within such simple frameworks.
} 
Figure 1: Optimal quality choice when $M V Q=P_{q}(s, q)$ decreases vs increases with quantity
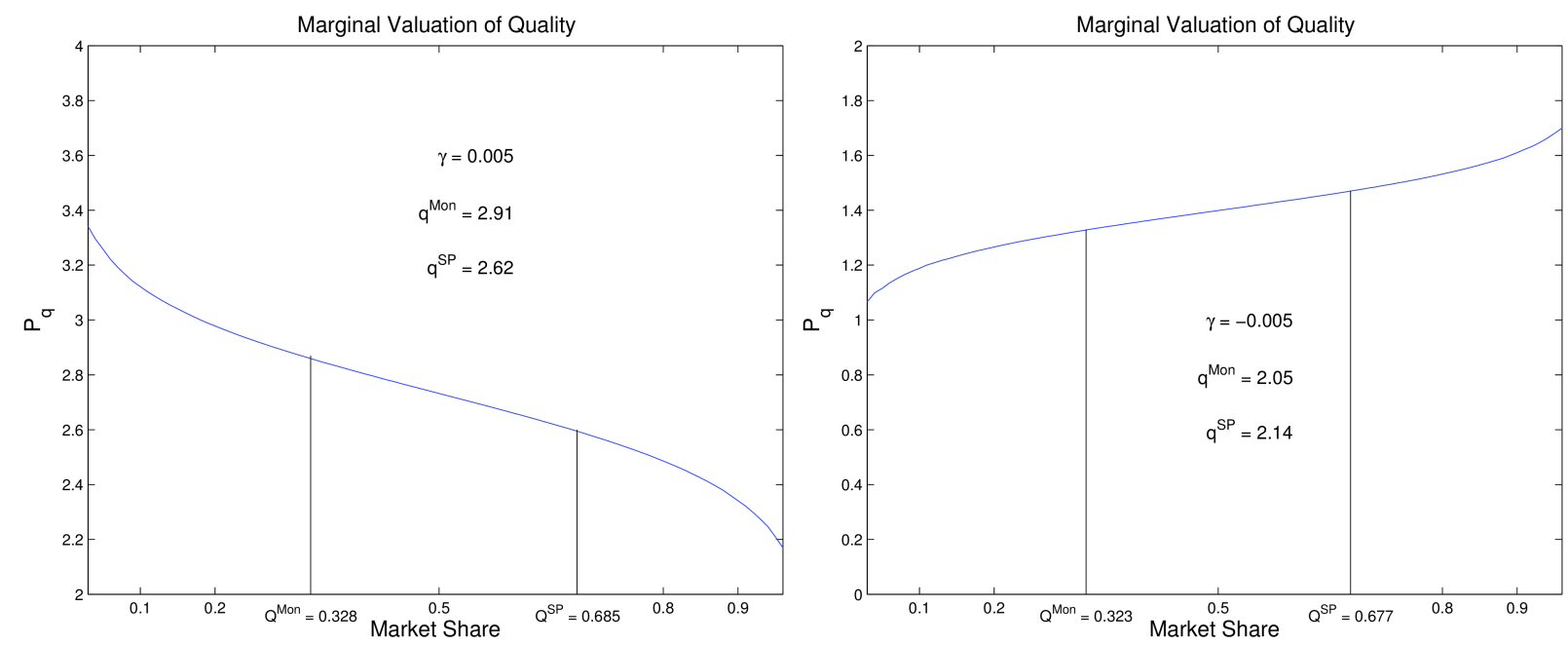

Notes: This figure shows how a single-product monopolist can over- or under-provide quality relative to a social planner. The two panels report the marginal valuation of quality, $\partial P(s, q) / \partial q$, or how much consumers' willingnessto-pay (WTP) $P(s, q)$ increases with increases in quality in a simple Logit model with a price-quality interaction term, $\gamma$ (see footnote 11). In the left panel, WTP for high-WTP consumers increases more with increases in quality, causing the monopolist to over-provide quality relative to a social planner. In the right panel, WTP for low-WTP consumers increases more with increases in quality, causing the monopolist to under-provide quality.

are no "Spence-ian" distortions at the top of the type distribution), (2) qualities to lower types are degraded downwards, (3) prices are set such that the lowest type receives no surplus, and (4) higher type earns positive surplus ("information rents").

Figure 2, adapted from Maskin and Riley (1984), provides the intuition for these results. ${ }^{14}$ The monopolist would like to offer the efficient qualities, $q_{j}^{* *}$, and set prices to extract all the surplus from each type, $p_{j}^{* *}$. Consumers prefer price-quality combinations to the southeast in the figure, however, and at these prices and qualities, the high type has an incentive to buy the low type's product. To prevent this from happening, the monopolist optimally keeps $q_{2}$ unchanged, but degrades $q_{1}$ until the high type is indifferent from choosing the low type's price-quality combination, $\left(p_{1}^{*}, q_{1}^{*}\right)$, and his own, $\left(p_{2}^{*}, q_{2}^{*}\right)$. He adjusts prices to keep utility to the low type at zero, but must lower prices to the high type, yielding for them positive rents $\left(p_{2}^{*}<p_{2}^{* *}\right)$.

\footnotetext{
${ }^{14}$ Maskin and Riley (1984) and Mussa and Rosen (1978) developed very similar models. The first analyzed optimal choice of prices and quantities while the latter analyzed optimal choice of prices and qualities.
} 
Figure 2: Optimal quality choice with three consumer types

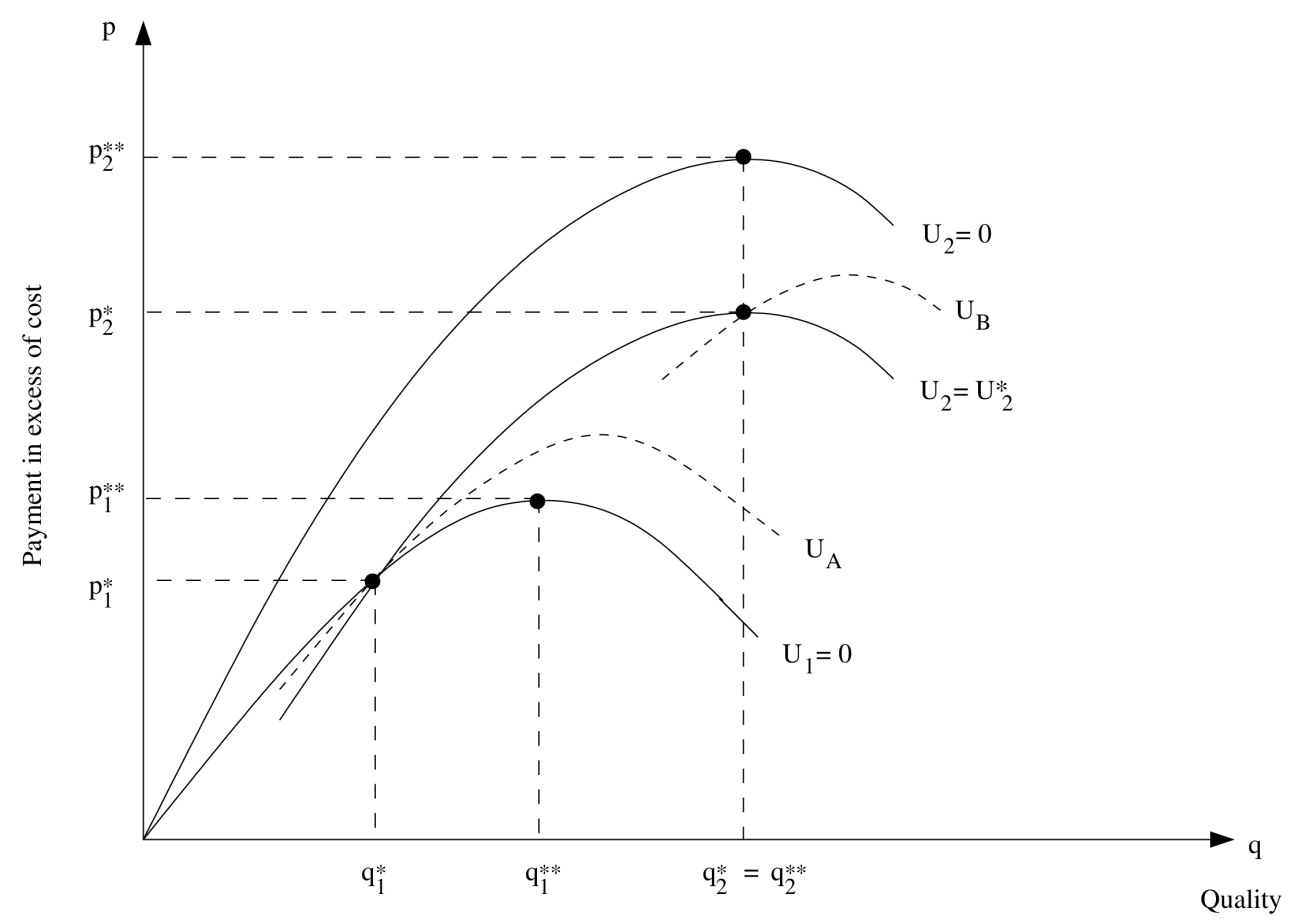

Notes: This figure, adapted from Maskin and Riley (1984), demonstrates the intuition underlying optimal quality choice by a multi-product monopolist facing three consumer types (only two of whom purchase products). The monopolist would prefer to offer prices and qualities denoted with $* *$ s and extract all surplus, but the high type (type 2) will prefer the low type's product (as utility to is increasing with higher quality and lower prices, i.e. as one moves southeast). To prevent this, he reduces quality to the low type $\left(q_{1}^{*}<q_{1}^{* *}\right)$, leaving quality to the high type unchanged (but lowering its price).

An important restriction in this model, and in most similar models in the theoretical literature, is the assumption of a single dimension of consumer heterogeneity. In the empirical work described below, we relax this assumption, allowing multiple dimensions of (correlated) consumer heterogeneity and, as we will see, our empirical results differ appreciably from these benchmark theoretical results.

\subsection{Quality markups and the welfare effects of market power over quality}

Quality markups. A price markup, given by the difference between a product's price and its marginal cost, is frequently used as a shorthand measure of market power over price at the marginal quantity (consumer). To understand the welfare consequences of market power over quality, we introduce here a similar measure. Let the total social benefit $(S B)$ associated with a given quality, $q$, quantity, $s$, and price, $P(s, q)$, be given by the sum of revenue and consumer 
surplus, ${ }^{15}$

$$
S B=\int_{0}^{s} P\left(s^{\prime}, q\right) d s^{\prime} .
$$

A price markup, $P(s, q)-c(q)$, is then just the difference between the marginal social benefit of an additional unit of quantity $(P)$ and the marginal social cost of that unit $(c(q)) .{ }^{16}$

We define analogously a quality markup. Let the marginal social benefit and marginal social cost of an additional unit of quality for a single-product monopolist be given by

$$
\begin{aligned}
& M S B \equiv \frac{\partial S B}{\partial q}=\int_{0}^{s} P_{q}\left(s^{\prime}, q\right) d s^{\prime} \\
& M S C \equiv \frac{\partial S C}{\partial q}=c_{q}(q) s
\end{aligned}
$$

Then a quality markup, $Q M$, in this setting is just the difference in these,

$$
Q M \equiv M S B-M S C=\int_{0}^{s} P_{q}\left(s^{\prime}, q\right) d s^{\prime}-c_{q}(q) s
$$

There are both similarities and differences between price and quality markups. Both measure the social losses due to market power at the margin and both are zero for the social planner and nonzero for the monopolist. An important difference is that, unlike price markups, quality markups for a monopolist can be negative. This depends on whether the $M V Q=P_{q}(s, q)$ increases or decreases with quantity among the monopolist's inframarginal consumers.

The welfare effects of market power over quality. Like a price markup, a quality markup is useful for characterizing the consequences of market power over quality at the margin. However, we also want to measure the consequences of market power over quality (and market power over price) for inframarginal consumers.

It is conceptually easy to calculate the total welfare effect of market power over both prices and qualities, i.e., $\Delta T S=T S\left(s^{S P}, q^{S P}\right)-T S\left(s^{M o n}, q^{M o n}\right)$, where $T S$ denotes total surplus and $S P$ and Mon stand for "social planner" and "monopolist" respectively.

The question remains, however, how we should "apportion" this total welfare effect between market power over price and market power over quality. We do so by defining

$$
\begin{aligned}
& M P Q^{*}=T S\left(p^{O B S}, q^{S P}\right)-T S\left(p^{O B S}, q^{O B S}\right), \\
& M P P^{*}=T S\left(p^{S P}, q^{S P}\right)-T S\left(p^{O B S}, q^{S P}\right),
\end{aligned}
$$

where $p^{O B S}$ and $q^{O B S}$ are the observed prices and qualities, $\left(p^{O b s}, q^{S P}\right)$ are the social planner's

\footnotetext{
${ }^{15}$ Equivalently, it is the area under the demand curve up to $s$. Total surplus is then just total social benefit minus cost, $c(s, q)$.

${ }^{16}$ Recall $C(s, q)=c(q) s$.
} 
optimal qualities given the observed prices, and $\left(p^{S P}, q^{S P}\right)$ are the social planner's jointly optimal prices and qualities, respectively. An advantage of this approach is that these two component parts add up to the same number as the total change in $T S$ from going from monopoly to the Social Planner levels for both prices and qualities. ${ }^{17}$ Specifically, defining

$$
T S^{*}=T S\left(p^{S P}, q^{S P}\right)-T S\left(p^{O B S}, q^{O B S}\right)
$$

then

$$
M P P^{*}+M P Q^{*}=T S^{*}
$$

which provides a natural way to decompose the total welfare effect into components arising from market power over price and market power over quality.

\section{Data and institutional details}

Cable television, formerly known as Community Antenna Television or CATV, emerged in the late 1940s in Arkansas, Oregon and Pennsylvania to deliver broadcast signals to the remote areas with poor over-the-air reception. ${ }^{18}$ In these areas homes were connected to the antenna towers located at the high points via cable network. Starting with 70 cable systems serving about 14,000 subscribers in 1952, a decade later almost 800 cable systems served about 850,000 subscribers (ibid.). According to FCC (2000), by October 1998 the number of cable systems reached 10,700 providing service to more than 65 million subscribers in 32,000 communities.

Until the 1990s, local cable systems were effectively natural monopolies as they faced virtually no competition except in a few cases of "overbuilt" systems where the same location was served by more than one cable company. Direct broadcast satellite (DBS) service was launched in the early 90 s and originally was popular mostly in rural areas where cable service did not exist. Since then the number of subscribers of DBS providers has experienced rapid growth.

Table 1: DBS penetration rates in 2001-2004

\begin{tabular}{lccc}
\hline & 2001 & 2004 & Change \\
\hline \hline Rural & $26 \%$ & $29 \%$ & $12 \%$ \\
Suburban & $14 \%$ & $18 \%$ & $29 \%$ \\
Urban & $9 \%$ & $13 \%$ & $44 \%$ \\
\hline \hline
\end{tabular}

Source: GAO report to the U.S. Senate, April 2005

\footnotetext{
${ }^{17}$ An alternative presented in a previous working paper version of this paper considered the welfare change from fixing one of prices and qualities at their observed level and setting the other at that chosen by the social planner, but this doesn't have the benefit of adding up to $\Delta T S$ defined above.

${ }^{18}$ See National Cable \& Telecommunications Association (NCTA), http://www.ncta.com/About/About/ HistoryofCableTelevision.aspx (accessed March 01, 2009).
} 
DBS and cable operators use different quality and price setting strategies. While each cable system makes pricing and quality decisions locally, satellite operators set these variables at the national level. It is conceivable though that there are other factors, like customer service as well as landscape and weather conditions that effect the quality of reception and attractiveness of the satellite service at regional level.

Cable television systems select a portfolio of programming networks, bundle them into one or more services and offer these services to households in local, geographically separate, cable markets. Systems typically offer three types of networks: broadcast networks, cable networks, and premium networks. ${ }^{19}$

Broadcast and cable networks are typically bundled by cable systems and offered as Basic Service. Some systems, however, elect to split up these networks and offer some portion of them as smaller bundles of networks known as Expanded Basic Services. Starting in the late 1990s, cable systems invested in digital technologies, allowing them to offer more television signals on a given infrastructure. At this time, they often introduced additional bundles of networks called Digital Basic Services. Despite the presence of separate Expanded and Digital Basic Services, households may not buy them directly. They are first required to purchase Basic Service.

An important feature of cable system management is their almost complete control over the content (quality) and price of their bundles. While certain regulations mandate systems carry all broadcast television stations available over the air in their service area (so-called MustCarry requirements), beyond these restrictions they may select and package whatever television networks they like for sale to households. With respect to prices, cable systems have been subject to cyclical regulatory oversight. ${ }^{20}$ Most recently, the 1996 Telecommunications Act removed price controls on Expanded and Digital Basic Services, leaving only Basic Service subject to (possible, though extremely weak) regulation.

The institutional and economic environment in the cable television industry suggests the choice of quality and price of Basic, Expanded Basic, and Digital Basic Services may map well to the theory. Since households that buy Expanded and Digital Basic Services must necessarily first purchase Basic Service, these services are by construction increasing in overall quality. Furthermore, since they consist of (generally large) bundles of individual networks, the range of qualities possibly chosen is plausibly continuous, and offered qualities are clearly discrete. ${ }^{21}$

\footnotetext{
${ }^{19}$ Broadcast networks are television signals broadcast in the local cable market and then collected and retransmitted by cable systems. Examples include the major, national broadcast networks - ABC, CBS, NBC, and FOX - as well as public and independent television stations. Cable networks are advertising-supported general and special-interest networks distributed nationally to systems via satellite, such as MTV, CNN, and ESPN. Premium networks are advertising-free entertainment networks, typically offering full-length feature films, such as HBO and Showtime.

${ }^{20}$ The most recent incident of price regulation was the 1992 Cable Act, the intent of which was to limit the prices charged for Basic and Expanded Basic Services. Due to a combination of factors, including strategic responses by cable systems to the imposed regulations and relatively weak cost pass-through ("going-forward") requirements, these provided little benefit to households (Hazlett and Spitzer (1997), Crawford (2000)).

${ }^{21}$ In a complementary line of analysis, Crawford (2008) and Crawford and Yurukoglu (2012) consider the in-
} 
As discussed above, competition in the multi-product television industry is somewhat atypical in that satellite providers choose to offer and price their products on a national basis, while their cable television competitors do so market-by-market. We model this difference by assuming that the evolution of satellite product and price options changes exogenously over time and that cable televisions systems respond strategically to these changes. Cable television systems in the presence of satellite competitors are still therefore monopolists, but now are monopolists on the residual demand curve remaining after accounting for satellite offerings. ${ }^{22}$

We have compiled a market-level dataset on a cross-section of United States cable systems to estimate the model. The primary source of data for these systems is Warren Publishing's Television and Cable Factbook Directory of Cable Systems. The data for this paper consists of the population of cable systems recorded in the 1997-2006 editions of the Factbook for which complete information was available. ${ }^{23}$ From the population, a sample of 3,931 systems remained.

Table 2 presents sample statistics for selected variable for these systems. Cable systems in the sample offer between one and three bundles, while satellite systems offer between three and six (with exactly three from 2002). As described earlier, the quality of a bundle is the weighted average of the number of television networks offered on that bundle, with weights given by the national average input cost ("affiliate fee") paid by cable systems for that network. As expected given the institutional structure of cable and satellite markets, prices and qualities are increasing across products.

An observation in the data is a cable system-year. As such, the computation of cablemarket-level satellite market shares deserves a separate discussion. Satellite penetration rates are available only at the Designated Market Area (DMA) level. ${ }^{24}$ Similar to Chu (2007), in order to compute satellite market share for each of the more narrowly defined markets we assume that within a DMA satellite subscribers constitute a constant proportion of the non-cable subscribers. ${ }^{25}$ The rationale for this assumption is related to the timing of the entry by DBS. In the

centives to bundle networks into Basic Services. This line of work tests the discriminatory incentives to bundle: namely that it by reducing heterogeneity in consumer tastes, bundling implicitly sorts consumers in a manner similar to 2nd-degree price discrimination.

${ }^{22}$ We could relax this assumption by allowing for strategic interaction between national aggregates of our cable systems and satellite operators. This would significantly increase the computational burden of the analysis, however, as it would require repeatedly solving for optimal prices and qualities of cable systems along the national satellite reaction functions until a full equilibrium is reached.

${ }^{23}$ While there are over 11,000 systems per year in the sample, persistence in non-response over time as well as incomplete reporting of critical variables required imposing a large number of conditions in order for a system to be included in each sample. Missing information on prices, quantities, and reporting dates were responsible for the majority of the exclusions.

${ }^{24}$ DMAs are measures of television markets defined by Nielsen and widely used in the sale of advertising. There are 210 mutually exclusive DMAs in the United States. Therefore there are many cable system markets within each DMA.

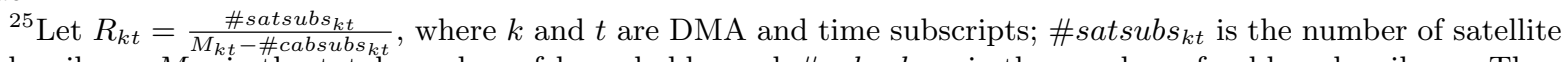
subscribers, $M_{k t}$ is the total number of households, and \#cabsubs $s_{k t}$ is the number of cable subscribers. Then satellite market share in market $j$ located in DMA $k$ is computed as $s_{j t}^{s}=\left(1-s_{j t}^{c}\right) R_{k t}$. 
Table 2: Data summary statistics, 1997-2006

\begin{tabular}{|c|c|c|c|c|}
\hline & Mean & StdDev & Min & Max \\
\hline \multicolumn{5}{|l|}{ Periods and Products } \\
\hline Time periods & 2.1 & 1.2 & 1 & 9 \\
\hline Cable products & 1.5 & 0.7 & 1 & 3 \\
\hline Satellite products & 5.2 & 1.4 & 3 & 6 \\
\hline \multicolumn{5}{|l|}{ Market shares } \\
\hline$s^{c}$ & 0.54 & 0.19 & 0.05 & 0.90 \\
\hline$s^{s}$ & 0.15 & 0.12 & 0.01 & 0.88 \\
\hline \multicolumn{5}{|l|}{ Prices } \\
\hline \multicolumn{5}{|l|}{ Cable } \\
\hline$p_{\text {Low }}^{c}$ & $\$ 20.44$ & $\$ 7.71$ & $\$ 2.68$ & $\$ 81.86$ \\
\hline$p_{M e d}^{c}$ & $\$ 32.77$ & $\$ 14.59$ & $\$ 7.88$ & $\$ 136.30$ \\
\hline$p_{\text {High }}^{c}$ & $\$ 60.28$ & $\$ 23.79$ & $\$ 16.90$ & $\$ 291.08$ \\
\hline \multicolumn{5}{|l|}{ Satellite } \\
\hline$p_{\text {Low }}^{s}$ & $\$ 21.69$ & $\$ 9.33$ & $\$ 14.44$ & $\$ 39.24$ \\
\hline$p_{M e d}^{s}$ & $\$ 27.15$ & $\$ 9.06$ & $\$ 19.26$ & $\$ 43.61$ \\
\hline$p_{\text {High }}^{s}$ & $\$ 45.95$ & $\$ 22.94$ & $\$ 28.89$ & $\$ 87.22$ \\
\hline \multicolumn{5}{|l|}{ Quality } \\
\hline \multicolumn{5}{|l|}{ Cable } \\
\hline$q_{\text {Low }}^{c}$ & 3.09 & 1.81 & 0.30 & 13.13 \\
\hline$q_{M e d}^{c}$ & 5.76 & 2.63 & 0.71 & 16.86 \\
\hline$q_{H i g h}^{c}$ & 9.11 & 3.45 & 2.34 & 19.02 \\
\hline \multicolumn{5}{|l|}{ Satellite } \\
\hline$q_{\text {Low }}^{s}$ & 5.12 & 3.49 & 1.78 & 11.73 \\
\hline$q_{M e d}^{s}$ & 6.48 & 3.16 & 3.30 & 12.67 \\
\hline$q_{\text {High }}^{s}$ & 10.77 & 6.51 & 5.65 & 27.88 \\
\hline \multicolumn{5}{|l|}{ Other Vars } \\
\hline Miles of plant & 0.160 & 0.560 & 0.000 & 17.690 \\
\hline Channel capacity & 44.9 & 20.2 & 5 & 542 \\
\hline \multicolumn{5}{|l|}{ Before 2002} \\
\hline$p_{\text {Tier } 3}^{s}$ & $\$ 35.98$ & $\$ 4.26$ & $\$ 32.75$ & $\$ 43.80$ \\
\hline$p_{\text {Tier } 4}^{s}$ & $\$ 41.10$ & $\$ 2.92$ & $\$ 38.53$ & $\$ 46.59$ \\
\hline$p_{\text {Tier } 5}^{s}$ & $\$ 54.67$ & $\$ 12.65$ & $\$ 46.23$ & $\$ 77.35$ \\
\hline$q_{\text {Tier } 3}^{s}$ & 7.42 & 1.78 & 5.93 & 10.44 \\
\hline$q_{\text {Tier } 4}^{S}$ & 8.01 & 1.75 & 6.53 & 10.96 \\
\hline$q_{\text {Tier } 5}^{s}$ & 9.45 & 3.49 & 6.96 & 15.44 \\
\hline
\end{tabular}

Notes: This table reports summary statistics for our estimation sample. Cable information is drawn from Warren Publishing's Television and Cable Factbook; satellite information was collected by hand. There are as many as six satellite products until 2001 and only three afterwards. Market shares reported in the table are aggregated across all products offered on each platform (cable, satellite). Prices are in 1997 dollars. Low, Medium, and High quality or price products are indexed by $\{0,1,2\}$ in the modeling section. The quality of a product is the weighted average of the number of television networks offered on that product, with weights given by the national average input cost ("affiliate fee") paid by cable systems for that network from SNL Kagan. 
first place, satellite providers targeted areas where there was no alternative cable paid-television service or where the cable share was small. Therefore, one can expect that within the same DMA satellite penetration is relatively larger in the areas franchised to the cable systems with smaller market shares. Typically, satellite penetration is greater in rural and suburban than in the densely populated urban areas where cable companies have greater market shares. ${ }^{26}$

Another important question is the definition of the quality of programming content offered by a particular provider. Using number of channels offered as a proxy for quality of the system's programming may be problematic as such a measure would not capture changes in the programming composition, holding the number of channels constant. In many cases, the data reveal that a lot of variation in the quality variable is due to the change in the composition of channels rather than due to change in the number of channels. In order to control for different compositions of channels we used data on the average cost of each channel negotiated between television networks and cable systems. ${ }^{27}$

Price data for cable and satellite services was adjusted using consumer price index with 1997 as the base year. Hence, any monetary equivalents computed in this paper are in 1997 prices.

\subsection{Preliminary evidence of quality degradation}

Unlike the case for price markups where one can in principle measure both prices and costs, there are not clear measures of quality markups in the data. The theory literature beginning with Mussa and Rosen (1978) connects market power with quality degradation for low-quality products offered by multi-product firms, and Crawford and Shum (2007, Table 3) investigated whether indeed prices-per-channel in cable markets were higher for low-quality cable services.

In Table 3, we present some exploratory evidence of quality degradation along the lines of Crawford and Shum (2007), using both their measure of product quality, price-per-channel, as well as the measure of product quality for which we advocate above, price-per-weighted-channel, with weights given by the national average input fee for each channel.

The evidence is largely inconclusive. While there is some evidence of higher prices-per-channel for lower-quality cable services, the significant heterogeneity in the raw underlying data prevents the differences from being statistically significant. As such, we are not able to point to clear evidence in the data for quality degradation.

Even were these differences significant, however, evidence of quality degradation would not necessarily inform by how much a monopolist distorts quality and, separately, prices from their efficient levels. Nor would it inform the welfare costs of these changes. In order to quantify these

\footnotetext{
${ }^{26}$ Another reason to expect lower satellite penetration in urban areas is the necessity to locate receiver (dish) in a place that guarantees open access to the orbital satellite. In urban areas it was harder due to the presence of multistory buildings that may impede receiving satellite beams. Besides in multi-unit structures up until recently to install a dish a resident must obtain permission of the home owner, which was not always an easy task.

${ }^{27}$ Channels with unknown or zero costs were assigned a cost of $\$ 0.01$.
} 
Table 3: Exploratory evidence of quality degradation

\begin{tabular}{|c|c|c|c|c|}
\hline & \multicolumn{2}{|c|}{ Three-Good Markets } & \multicolumn{2}{|c|}{ Two-Good Markets } \\
\hline & Mean & Diff & Mean & Diff \\
\hline \multicolumn{5}{|l|}{ Prices-per-channel } \\
\hline$p_{2} /$ channels $_{2}$ & $1.28(0.64)$ & $0.46(0.34)$ & $1.38(0.82)$ & $-0.31(1.50)$ \\
\hline$p_{1} /$ channels $_{1}$ & $0.81(0.40)$ & $-0.42(0.87)$ & $1.69(1.50)$ & \\
\hline$p_{0} /$ channels $_{0}$ & $1.23(1.04)$ & & & \\
\hline \multicolumn{5}{|l|}{ Prices-per-weighted-channel } \\
\hline$p_{2} / q_{2}$ & $7.27(2.74)$ & $2.03(1.74)$ & $6.60(2.39)$ & $-4.26(10.02)$ \\
\hline$p_{1} / q_{1}$ & $5.24(2.21)$ & $-5.11(7.52)$ & $10.86(10.20)$ & \\
\hline$p_{0} / q_{0}$ & $10.34(8.21)$ & & & \\
\hline Observations & & & & \\
\hline
\end{tabular}

Notes: Reported are the average price per channel and price per weighted channel for each offered cable service in our estimation sample. Weights are given by the national average input cost for that channel in the relevant year. Values in the "Difference" columns are the difference in price per channel in that row and the row that follows. Standard errors are in parentheses.

costs, one must specify a structural model of demand, pricing, and quality choice, both for a monopolist and a social planner and directly measure these differences. That is the purpose of the model we introduce in the next section.

\section{Model}

Consider a market, $n$, served by two providers of paid television service - cable and satellite, denoted with $g \in\{c, s\}$, each offering multiple products indexed by $j \in \mathcal{J}_{g n} .{ }^{28}$ One can characterize a multi-product cable carrier offering $J_{n}$ distinct products by their monthly subscription fees, $p_{j n}$, and quality of programming content, $q_{j n}$, which we assume can be summarized by a scalar.

\subsection{Demand}

There are a continuum of consumers, indexed by $i$, whose preferences for a product $j$ offered by a provider $g$ depend on the monthly subscription fee, $p_{j g n}$, and service quality, $q_{j g n}$, of that product. Let $i$ 's indirect utility function be given by

$$
U_{i j g n}=\left\{\begin{array}{c}
\delta_{j g n}\left(p_{j g n}, q_{j g n}, \bar{Y}_{i n}, \xi_{g n} ; \omega_{i}\right)+\epsilon_{i g n}, \text { for product } j \text { of provider } g \text { in market } n \\
\epsilon_{i 0 n}, \text { otherwise }
\end{array}\right.
$$

\footnotetext{
${ }^{28}$ While our data vary by both geography and time, there are relatively few systems with multiple observations across years. We therefore treat it as a single cross-section and omit a time subscript from the model.
} 
where $\omega_{i}$ denotes consumer $i$ 's heterogeneous preferences. ${ }^{29}$ These are assumed to be known to consumer $i$, but unobserved by the econometrician. $\xi_{g n}$ denotes unobserved characteristics of provider $g$ in market $n$, and $\bar{Y}_{i n}$ is a vector of observable demand shifters (e.g. consumer demographics). Both the unobserved characteristics, $\xi_{g n}$, and the idiosyncratic preference draw, $\epsilon_{i g n}$, are provider-specific and not product-specific (i.e. both depend on $g$ instead of $j$ ). We assume $\epsilon_{i g n}$ is distributed at as Type I Extreme Value.

\subsubsection{Total provider shares}

Let $\bar{p}_{g n}$ and $\bar{q}_{g n}$ denote observable vectors of prices and quality levels for all products offered by provider $g \in\{c, s\}$ in market $n$ and let the maximum utility a consumer type $i$ achieves by choosing among the products offered by provider $g$ be given by

$$
\delta_{g n}\left(\bar{p}_{g n}, \bar{q}_{g n}, \bar{Y}_{i n}, \xi_{g} ; \omega_{i}\right)=\max _{j^{\prime} \in \mathcal{J}_{g n}}\left\{\delta_{j^{\prime} g n}\left(p_{j^{\prime} g n}, q_{j^{\prime} g n}, \bar{Y}_{i n}, \xi_{g n} ; \omega_{i}\right)\right\}
$$

Because $\epsilon_{i g n}$ is common to all the indirect utilities, $U_{i j^{\prime} g n}, \forall j^{\prime} \in \mathcal{J}_{g n}$, it doesn't influence the choice of product within provider for consumer type $i$.

The probability that a consumer of type $i$ chooses $g$ in $n$ is given by the standard Logit formula

$$
P_{g n}\left(\omega_{i}\right)=\frac{\exp \left(\delta_{g n}\left(\bar{p}_{g n}, \bar{q}_{g n}, \bar{Y}_{i n}, \xi_{g n} ; \omega_{i}\right)\right)}{1+\exp \left(\delta_{c n}\left(\bar{p}_{c n}, \bar{q}_{c n}, \bar{Y}_{i n}, \xi_{c n} ; \omega_{i}\right)\right)+\exp \left(\delta_{s n}\left(\bar{p}_{s n}, \bar{q}_{s n}, \bar{Y}_{i n}, \xi_{s n} ; \omega_{i}\right)\right)} .
$$

and the aggregate market share of $g$ in $n$ is obtained by integrating over the distribution of consumer heterogeneity, $d F\left(\omega_{i}\right)$ :

$$
s_{g n}=\int \frac{\exp \left(\delta_{g n}\left(\bar{p}_{g n}, \bar{q}_{g n}, \bar{Y}_{i n}, \xi_{g n} ; \omega_{i}\right)\right)}{1+\exp \left(\delta_{c n}\left(\bar{p}_{c n}, \bar{q}_{c n}, \bar{Y}_{i n}, \xi_{c n} ; \omega_{i}\right)\right)+\exp \left(\delta_{s n}\left(\bar{p}_{s n}, \bar{q}_{s n}, \bar{Y}_{i n}, \xi_{s n} ; \omega_{i}\right)\right)} d F\left(\omega_{i}\right) .
$$

From the definition of $\delta_{g n}(\cdot)$ and equation (14) it follows that

$$
s_{g n}=s_{g n}\left(\bar{p}_{c n}, \bar{q}_{c n}, \bar{p}_{s n}, \bar{q}_{s n}, \bar{Y}_{n}, \xi_{c n}, \xi_{s n} ; \theta_{d}\right),
$$

where $\xi_{c n}$ and $\xi_{s n}$ are the only two unobservable to the econometrician provider characteristics and $\theta_{d}$ is a vector of demand parameters that includes parameters governing the distribution of $\omega_{i}$ and measuring the influence of demographic variables, $\bar{Y}_{n}$. Under standard assumptions, we can use the Berry (1994) and Berry et al. (1995) inversion to solve the system of equations

$$
\left\{\begin{array}{r}
s_{c n}=s_{c n}\left(\bar{p}_{c n}, \bar{q}_{c n}, \bar{p}_{s n}, \bar{q}_{s n}, \bar{Y}_{n}, \xi_{c n}, \xi_{s n} ; \theta_{d}\right), \\
s_{s n}=s_{s n}\left(\bar{p}_{c n}, \bar{q}_{c n}, \bar{p}_{s n}, \bar{q}_{s n}, \bar{Y}_{n}, \xi_{c n}, \xi_{s n} ; \theta_{d}\right)
\end{array}\right.
$$

\footnotetext{
${ }^{29}$ In the empirical model below, they will include random coefficients on price and quality.
} 
for a pair $\left(\xi_{c n}, \xi_{s n}\right)$ that makes observed cable and satellite market shares (left-hand-side variables) equal to the ones predicted by our model.

\subsubsection{Conditional product-specific shares}

In the data, we observe product-specific (tier-specific) market shares for cable systems, not just provider-specific shares. ${ }^{30}$ They are clearly informative about consumer price and quality preference parameters. In fact, from equation (12), the only way our model predicts non-degenerate conditional (on the choice of provider) product-specific shares is if tastes for price and/or quality differ across consumer types.

Let $P_{j g n}\left(\omega_{i}\right)$ denote the probability that consumer type $i$ chooses product $j$ of provider $g$ in market $n$. Then market share of product $(j, g, n)$ is given by

$$
s_{j g n}=\int P_{j g n}\left(\omega_{i}\right) d F\left(\omega_{i}\right)
$$

Let $s_{j \mid g, n}$ denote the market share of tier $j$ given the choice of provider $g$ with $\sum_{j \in \mathcal{J}_{g n}} s_{j \mid g, n}=$ 1 by construction. Then the model's prediction for this share is described by the following equation

$$
s_{j \mid g, n}=\frac{\int \mathbb{1}\left(j=\arg \max _{j^{\prime} \in \mathcal{J}_{g}}\left\{\delta_{j^{\prime} g}\left(p_{j^{\prime} g}, q_{j^{\prime} g}, \bar{Y}_{i n}, \xi_{g} ; \omega_{i}\right\}\right) P_{g n}\left(\omega_{i}\right) d F\left(\omega_{i}\right)\right.}{\int P_{g n}\left(\omega_{i}\right) d F\left(\omega_{i}\right)}
$$

There are no "structural" errors in the predictions of product-specific shares. Conditional on observables, the only way to explain the difference in predictions is measurement error:

$$
s_{j \mid g, n}=s_{j \mid g, n}\left(\bar{p}_{c n}, \bar{q}_{c n}, \bar{p}_{s n}, \bar{q}_{s n}, \bar{Y}_{n}, \xi_{c n}, \xi_{s n} ; \theta_{d}\right)+u_{j g n}, \quad \text { s.t. } E\left[u_{j g n} \mid \mathcal{I}_{t}\right]=0
$$

where $\mathcal{I}_{t}$ stands for all available information at time $t$.

\subsection{Supply}

As discussed in Section 3, in each market paid television service is provided by two satellite carriers and a single cable company. Due to data limitations, however, we have to aggregate the two satellite providers into a single entity called "satellite". Hence, we model each market as a duopoly with one local cable system and one national satellite provider.

Consistent with the demand side of the model discussed in Section 4.1, we model optimal price and quality decisions by the local cable system in each market, $n$. Before we discuss this maximization problem, we make another simplifying assumption.

\footnotetext{
${ }^{30}$ We do not, unfortunately, observed satellite tier-specific shares in our data.
} 
Assumption 1: The satellite competitor is a nonstrategic player in the sense that it does not react to policies (prices, qualities) chosen by local cable systems.

Assumption (1) allows us to abstract away from modeling optimal satellite policies and treat them as exogenous from the cable system standpoint.

On the cable side, we assume that per-subscriber marginal cost of providing product $j$ in market $n$ is

$$
m c_{j c n}=m c\left(q_{j c n}, Z_{c n} ; \theta_{s}\right)
$$

where $Z_{c n}$ denotes a vector of observable cost shifters, and $\theta_{s}$ is a vector of supply-side cost parameters. Together with the assumption that market size does not change over time, this allows us to write the maximization problem for a cable system as follows

$$
\max _{\left\{p_{j c n}, q_{j c n}\right\}_{j \in \mathcal{J}_{c n}}}\left\{\sum_{j \in \mathcal{J}_{c n}} s_{j c n}\left(\bar{p}_{c n}, \bar{q}_{c n}, \bar{p}_{s n}, \bar{q}_{s n}, \xi_{c n}, \xi_{s n} ; \theta_{d}\right)\left(p_{j c n}-m c\left(q_{j c n}, Z_{c n} ; \theta_{s}\right)\right)\right\}
$$

This specification assumes that the marginal quantity cost of providing cable service is constant across subscribers (i.e. no economies or diseconomies of scale), but that this (constant) marginal cost increases with the quality of the offered service. This specification fits well the cable industry where the most important marginal costs facing systems are the input costs ("affiliate fees") paid to television networks, the structure of which are uniformly a constant per-subscriber fee. ${ }^{31}$

The first-order conditions for the cable controls are then given by the following system of equations:

$$
\begin{aligned}
& \text { F.O.C. }\left[p_{j c n}\right]: \quad s_{j c n}+\sum_{r \in \mathcal{J}_{c n}}\left(p_{r c n}-m c_{r c n}\right) \frac{\partial s_{r c n}}{\partial p_{j c n}}=0 \\
& \text { F.O.C. }\left[q_{j c n}\right]: \quad-\frac{\partial m c_{j c n}}{\partial q_{j c n}} s_{j c n}+\sum_{r \in \mathcal{J}_{c n}}\left(p_{r c n}-m c_{r c n}\right) \frac{\partial s_{r c n}}{\partial q_{j c n}}=0
\end{aligned}
$$

Under standard regularity conditions, (20) and (21) can be solved for the marginal cost levels, $m c_{j c n}$, and the derivatives of the marginal cost function, $\partial m c_{j c n} / \partial q_{j c n}$, that rationalize observed price and quality choices given the parameters of the model (see 5.2). We discuss the specification of the marginal cost function in Section 5.2.

We take the number of products offered by each cable system as given and exogenous to systems' price and quality decisions. We feel it is reasonable in cable markets because the

\footnotetext{
${ }^{31}$ See Crawford and Yurukoglu (2012) for more details about these contracts.
} 
number of products offered by cable systems often depends on the technology the system has in place and is therefore plausibly exogenous to annual price and quality decisions. ${ }^{32}$

\section{Specification and estimation}

Here we provide some specification details for the consumers' utility and cable systems' cost functions.

\subsection{Demand}

On the demand side, we assume that consumer utility net of additive iid shocks $\epsilon_{i g n}$ is a linear function of price, quality, and demographic characteristics, $\bar{Y}_{i n}$

$$
\delta_{j g n}\left(p_{j g n}, q_{j g n}, \bar{Y}_{i n}, \xi_{g} ; \omega_{i}\right)=\alpha_{g}+\alpha_{i p}\left(\bar{Y}_{i n}\right) p_{j g n}+\alpha_{i q}\left(\bar{Y}_{i n}\right) q_{j g n}+\xi_{g n}
$$

where

$$
\begin{aligned}
& \alpha_{i p}=a_{i 0}+a_{y} I_{n}+a_{h} H_{n}+a_{u} U_{n} \\
& \alpha_{i q}=b_{i 0}+b_{y} I_{n}+b_{h} H_{n}+b_{u} U_{n}
\end{aligned}
$$

and $I_{n}$ stands for income, $H_{n}$ for household size, and $U_{n}$ for the level of urbanization in market $n$. These market-level variables are assumed to have the same effect on the price and quality sensitivity parameters for all consumer types. Two additional parameters $a_{i 0}$ and $b_{i 0}$ are $i$-specific and have a flexible variance-covariance matrix, i.e.,

$$
\left(\begin{array}{l}
a_{i 0} \\
b_{i 0}
\end{array}\right) \sim N\left(\begin{array}{l}
\bar{a}_{0} \\
\bar{b}_{0}, \Sigma
\end{array}\right), \quad \Sigma=\left(\begin{array}{ll}
\sigma_{a}^{2} & \rho_{a b} \\
\rho_{a b} & \sigma_{b}^{2}
\end{array}\right)
$$

Demand estimation therefore requires estimating the following list of parameters,

$$
\theta_{d}=\left(\alpha_{c}, \alpha_{s},\left[\bar{a}_{0}, a_{y}, a_{h}, a_{u}\right],\left[\bar{b}_{0}, b_{y}, b_{h}, b_{u}\right], \sigma_{a}, \sigma_{b}, \rho_{a b}\right)
$$

The direction and magnitude of market power over quality are determined by a large number of structural parameters that are allowed to vary across markets with average demographics and by the correlation of random components, $a_{i 0}$ and $b_{i 0}$. This is a deviation from the single dimension of preferences often assumed in theory models of endogenous quality choice and will be an important factor rationalizing the differences in results we get relative to this literature.

\footnotetext{
${ }^{32}$ Similar timing assumptions are invoked in the empirical measurement of productivity (e.g. Olley and Pakes (1996), Ackerberg et al. (2006)).
} 


\subsection{Supply}

In order to evaluate the counterfactuals for the social planner's quality choices, we need to know what the cable operators' entire marginal cost function is, not just the costs at the observed quality levels. Hence, we specify a flexible yet parsimonious cost function and estimate its parameters. Therefore, we assume the marginal cost function of a cable provider and its derivative with,

$$
\begin{gathered}
m c\left(q_{j c n}, Z_{c n} ; \theta_{s}\right)=\exp \left(c_{0 j n}+c_{1 j n} q_{j c n}\right) \\
\frac{\partial m c\left(q_{j c n}, Z_{c n} ; \theta_{s}\right)}{\partial q_{j c n}}=c_{1 j n} \exp \left(c_{0 j n}+c_{1 j n} q_{j c n}\right)
\end{gathered}
$$

where $c_{0 j n}=c_{0}\left(Z_{c n}, \nu_{0 j c n}\right)$ and $c_{1 j n}=c_{1}\left(Z_{c n}, \nu_{1 j c n}\right)$ are linear functions of observable cost shifters and a pair of structural error terms, $\left(\nu_{0 c n}, \nu_{1 c n}\right) .{ }^{33}$ In order to isolate the cost errors, for a given vector of parameter values, we invert out a system of first order conditions to obtain $\widehat{m c}_{j c n}$ and $\partial \widehat{m c}_{j c n} / \partial q_{j c n}$, which are then used to compute $\hat{c}_{0 j n}$ and $\hat{c}_{1 j n}$ as follows,

$$
\begin{aligned}
\hat{c}_{0 j n} & =\ln \left(\widehat{m c}_{j c n}\right)-\frac{\partial \widehat{m c}_{j c n} / \partial q_{j c n}}{\widehat{m c}_{j c n}} q_{j c n}, \\
\hat{c}_{1 j n} & =\frac{\partial \widehat{m c}_{j c n} / \partial q_{j c n}}{\widehat{m c}_{j c n}}
\end{aligned}
$$

Finally, we regress $\hat{c}_{0 j n}$ and $\hat{c}_{1 j n}$ on $Z_{c n}$, i.e.,

$$
\begin{aligned}
& \hat{c}_{0 j n t}=Z_{j n t} \theta_{s 0}+v_{0 j n t}, \\
& \hat{c}_{1 j n t}=Z_{j n t} \theta_{s 1}+v_{1 j n t},
\end{aligned}
$$

to obtain $\nu_{1 j c n}$ and $\nu_{2 j c n}$ under assumption that

$$
\mathrm{E}\left[\nu_{0 j n} \mid Z_{c n}\right]=\mathrm{E}\left[\nu_{1 j n} \mid Z_{c n}\right]=0
$$

It is worth noting that the particular functional form chosen for the marginal cost function is not critical for the identification of the parameters in our model. It is possible to be very flexible when specifying a parametric form for $m c\left(q_{j c n}, Z_{c n} ; \theta_{s}\right)$. Since we never observe more than 3 products per firm and would like to make out-of-sample predictions in our counterfactual simulations, we use the parsimonious specification given by equations (26) and (27). ${ }^{34}$ Our choice of the function forms is similar to the one used in the literature (e.g., Berry et al. 1995). In addi-

\footnotetext{
${ }^{33}$ We refer to the errors as "structural" because they are observed by cable system before price and quality decisions are made.

${ }^{34}$ In principle, if we were to observe a very large number of products for each producer, we would be able to recover the marginal cost function at a large number of points and use a less parsimonious specification.
} 
tion, exponentiation of the quality level is consistent with the cable systems facing technological capacity constraints when adding high quality networks into their channel lineup.

\subsection{Instruments and identification}

As we discussed in Section 4.1, for each value of the parameter vector $\theta_{d}$, we solve for a pair of provider-specific structural errors, $\left(\xi_{c n}, \xi_{s n}\right)$, and a set of non-structural "measurement errors", $u_{j c n}$, for cable providers using aggregate cable and satellite market shares, prices and observed quality levels for each tier offered, and tier-specific cable market shares. On the supply side, we solve for a level of marginal cost and its derivative (at the observed quality level) per product offered by the cable system. Assuming piece-wise exponential cost functions, we transform these quantities into a "marginal cost shifter", $c_{0 j n}$, and a "marginal cost rotator", $c_{0 j n}$, which are

then projected onto a vector of observable cost shifters $\bar{Z}_{c n}$, to obtain $\left(\nu_{1 j n}, \nu_{2 j n}\right)$. Identification of the structural parameters relies on a set of conditional independence assumptions summarized by Assumption 2 below.

Assumption 2: Unobservables and identifying assumptions.

(2.1) For each service provider $g$ in market $n$, the unobserved service characteristics can be written as

$$
\xi_{g n}=\bar{\alpha}_{g}+\alpha_{g t}+\tilde{\xi}_{g n}
$$

where $\bar{\alpha}_{g}$ is provider-specific intercept, $\alpha_{g t}$ is provider-specific time effect, and $\left(\tilde{\xi}_{c n}, \tilde{\xi}_{s n},\right)$ satisfy the following mean independence assumptions

$$
\mathrm{E}\left[\tilde{\xi}_{c n} \mid \bar{Z}_{c n}\right]=\mathrm{E}\left[\tilde{\xi}_{s n} \mid \bar{Z}_{s n}\right]=0 .
$$

(2.2) Measurement errors for markets with 2 and 3 cable products satisfy

$$
\mathrm{E}\left[u_{c j n} \mid \bar{Z}_{c n}\right]=0, j=1,2 .
$$

(2.3) Supply side cost shocks for each product offered are linear functions of cost shifters,

$$
\begin{aligned}
& c_{0 j n}=Z_{c n} \theta_{s 0}+\nu_{0 j n}, \\
& c_{1 j n}=Z_{c n} \theta_{s 1}+\nu_{1 j n},
\end{aligned}
$$

where

$$
\mathrm{E}\left[\nu_{0 j n t} \mid \bar{Y}_{n t}, Z_{c n}\right]=\mathrm{E}\left[\nu_{1 j n t} \mid \bar{Y}_{n t}, Z_{c n}\right]=0 .
$$


There is an obvious endogeneity problem because cable companies observe realizations of $\left(\xi_{c n}, \xi_{s n}\right)$ prior to making their price and quality choices. Therefore, prices and qualities are likely to be correlated with the unobserved service characteristics, $\xi_{c n}$ and $\xi_{s n}$. In order to find instruments for the demand-side estimation we use the following four arguments. The discussion here is similar to that used recently in Shcherbakov (2012).

First, following Crawford (2008), we assume that the average prices and quality levels of other cable systems that belong to the same multiple system operator (MSO) are valid instrumental variables for prices and quality levels of the local provider. We assume that these variables are uncorrelated with the unobserved local market service characteristics, $\xi_{\cdot n}$, but are reasonable proxies for the price and quality levels offered by the local cable system. Correlation in prices and quality levels across systems exists because the owner of several cable systems typically negotiates programming fees and other contract arrangements with programming networks on behalf of all of its members simultaneously. In turn, correlation in the marginal costs of systems within the same MSO justifies correlation in their price and quality levels. At the same time, for the instruments to be valid, one must ensure that the unobserved demand shocks, $\xi_{\cdot n}$ are not correlated across markets. For example, this would be a concern if there were national advertising of cable products across the markets owned by a single MSO; fortunately for this specification, this is not the case in cable markets during our sample period. Crawford (2008) discusses this class of instruments in detail and argues why they should work well in cable markets.

Second, different MSOs have different bargaining power in negotiations with programming networks. It may be that larger MSOs (i.e. those with more total subscribers) have stronger bargaining position. Hence, we use the number of MSO subscribers as a cost shifter. ${ }^{35}$ Third, programming networks often sell bundles consisting of several channels. The ability to purchase such bundles depends on the system's channel capacity. Thus, average channel capacity within an MSO should be correlated with the ability of their member-systems to get lower rates. By the same logic, we used own capacity level as another instrumental variable. Fourth, total length of own coaxial lines of the local cable systems is a proxy for the differences in maintenance costs incurred by the systems in areas with different densities of houses.

Our baseline set of instruments includes all of these variables. To demonstrate the effects of the instruments and for robustness, however, we also consider (results reported in the appendix) specifications in which all variables instrument for themselves (hereafter "OLS-type" instruments) and using a minimal set of instruments consisting only of the ownership-based (MSO) instruments (hereafter "min-IV").

\footnotetext{
${ }^{35}$ Crawford and Yurukoglu (2012) found that large MSOs were estimated to have more bargaining power than small MSOs and satellite providers.
} 


\subsubsection{Moment conditions}

There are three sets of moment conditions as described by Assumption (2): (1) moments associated with the unobserved product characteristics (i.e., demand-side shocks), (2) moments associated with the supply-side shocks, and (3) "measurement errors" resulting from approximating conditional cable shares. Define

$$
\begin{aligned}
G_{c}(\theta) & =\mathrm{E}\left[\tilde{\xi}_{c n t}(\theta) \cdot \bar{Z}_{c n t}\right], \\
G_{s}(\theta) & =\mathrm{E}\left[\tilde{\xi}_{s n t}(\theta) \cdot \bar{Z}_{s n t}\right], \\
G_{u}(\theta) & =\mathrm{E}\left[u_{c j n t}(\theta) \cdot \bar{Z}_{n t}\right], \\
G_{v}(\theta)= & \mathrm{E}\left[\left(v_{1 j n t}, v_{2 j n t}\right)^{\prime} \cdot \bar{Y}_{n t}\right]
\end{aligned}
$$

to represent population moment conditions where $G^{N}(\theta)=\left(G_{c}^{N}(\theta), G_{s}^{N}(\theta), G_{u}^{N}(\theta), G_{v}^{N}(\theta)\right)$ stand for their sample analogs.

The measurement errors in conditional cable product shares are uncorrelated with other variables by definition. We also assume no correlation between demand- and supply-side innovations. However, it is conceivable that demand side unobservables for cable and satellite are correlated with each other, i.e., $\operatorname{cov}\left(\xi_{\text {cnt }}, \xi_{\text {snt }}\right) \neq 0$. We exploit this information when constructing the weighting matrix and criterion function for the estimation. In particular, individual moments based on $\tilde{\xi}_{c n t}$ and $\tilde{\xi}_{\text {snt }}$ are "stacked" horizontally and are treated as distinct moment conditions, i.e., averaging is done separately for cable and satellite moments. ${ }^{36}$

Structural parameters are estimated using two-step optimal GMM, i.e.,

$$
\hat{\theta}=\underset{\theta \in \Theta}{\arg \min } G^{N}(\theta)^{\prime} W G^{N}(\theta)
$$

where $W$ is a block-diagonal weighting matrix.

\section{$6 \quad$ Estimation results}

\subsection{Parameter Estimates}

Demand. Table 4 summarizes our estimation results for two specifications. Specification (2) includes demographics at the market level, while specification (1) does not.

Demographic variables appear to be quite important determinants of the price sensitivity, while they are not statistically significant when used to explain preferences for quality. Parameters of the unobserved consumer heterogeneity turn out to be statistically significant with the

\footnotetext{
${ }^{36}$ In contrast, in Berry et al. (1995) and the following literature, the averaging for the moment conditions is across the available products, which in our case would be the cable and satellite products.
} 
Table 4: Estimation results

\begin{tabular}{lcccc}
\hline \multirow{2}{*}{ parameter } & \multicolumn{2}{c}{$(1)$} & \\
\cline { 2 - 5 } & coef. & s.e. & coef. & s.e. \\
\hline \hline price coefficient, $\alpha_{i p}$ & & & & \\
\hline mean & -0.673 & $(0.001)$ & -0.682 & $(0.023)$ \\
income & & & -0.418 & $(0.091)$ \\
h-size & & 0.396 & $(0.062)$ \\
urban & & & -0.173 & $(0.017)$ \\
sigma & 0.102 & $(0.006)$ & 0.122 & $(0.013)$ \\
\hline quality coefficient, $\alpha_{i q}$ & & & & \\
\hline mean & 1.108 & $(0.032)$ & 1.225 & $(0.083)$ \\
income & & & -0.337 & $(0.413)$ \\
h-size & & & 0.221 & $(0.144)$ \\
urban & & & 0.331 & $(0.184)$ \\
sigma & 0.310 & $(0.007)$ & 0.266 & $(0.007)$ \\
\hline corr $\left(a_{i p}, a_{i q}\right)$ & -0.545 & $(0.032)$ & -0.481 & $(0.090)$ \\
\hline demand t-dummies & Yes & & Yes & \\
supply t-dummies & Yes & & Yes & \\
\hline \hline
\end{tabular}

Notes: Reported are estimation results for key parameters from our structural model of demand, price, and quality choice. There are 12,214 observations, where an observation is a cable system-product-year. Full estimation results can be found in Appendix C. Specification (1) does not include market demographics in preferences, while specification (2) does. Instruments include all those described in Section 5.3; results using each variable as its own instrument (OLS-type) and a minimal set of instruments based on ownership (MSO) measures (min-IV) are presented in Appendix A. Standard errors are in parentheses. 
tastes for quality having much wider dispersion than price sensitivity as follows from the estimates of their standard deviations. Figure 3 describes variation in estimated price and quality parameters across markets.

Figure 3: Distributions of mean price and quality parameters across markets.
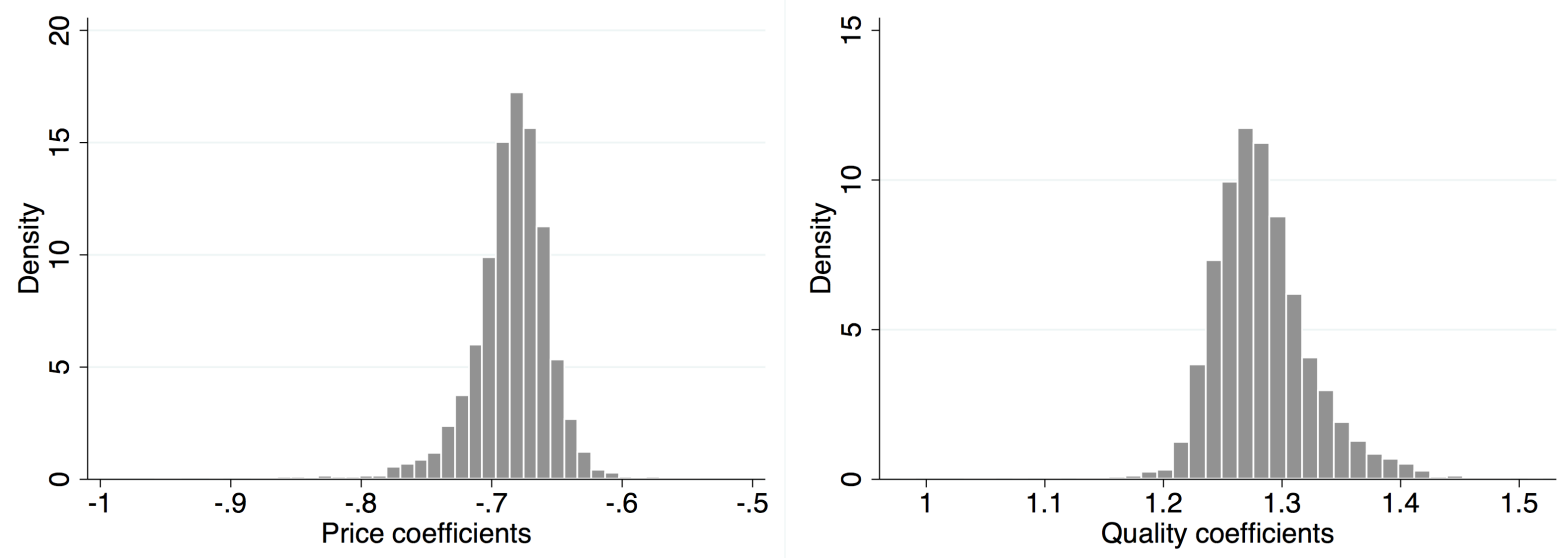

Notes: Reported are the estimated distributions of mean price and quality parameters across markets implied by the parameter estimates reported in Table 4.

Demographic variables also explain some (but not all) of the estimated correlation between household tastes for price and quality. Without demographic controls, this correlation is an estimated -0.545 , indicating those with the most price sensitivity also have the greatest quality sensitivity. Following the discussion in Section 2, this is one of the key inputs into whether cable systems over- or under-provide quality relative to the social planner. ${ }^{37}$ Once market-level demographics are included, the correlation in unobserved tastes for price and quality falls (in magnitude) to an estimated -0.481 .

Estimated median own-price elasticities across markets are -4.2 for low-quality, -20.3 for medium-quality, and -8.1 for high-quality products, slightly higher than those found in previous research in cable markets using similar data. Histograms and further summary statistics for own price elasticities across markets are reported in Appendix B. Average estimated price-cost markups implied by these elasticity estimates are reported below in Table 6 .

Results for two alternative specifications (OLS-like and min-IV) are reported in Appendix A. Using price and quality as instruments for themselves yields a mean price coefficient of -0.553 , showing that instrumenting has the expected effect of making the estimated demand more elastic. Using a minimal set of instruments yields qualitatively similar results, but with larger standard errors. For this reason, in the results that follow we rely on our baseline specification presented in column (2) above.

\footnotetext{
${ }^{37}$ The other being the extent of quantity reduction under monopoly.
} 
Supply. The estimated distributions of marginal costs and their derivatives at observed quality levels are reported in Table 5. These suggest substantial variability in terms of technology levels (as implied by the cost function estimates) used by the cable systems. Based on these estimates, we use flexible polynomial (Hermite) interpolation between the observed quality levels to construct an estimate of the entire marginal cost function for cable operators. To illustrate the differences across system types implied by the estimates, we draw cost functions for one-, two- and three-product systems in Figure 4. As is apparent, high quality systems on average employ more advanced technology resulting in lower marginal costs for all quality levels as well as in less steep slope of the marginal cost curve. Similar differences in the shapes of the marginal cost functions are found for other multi-product service providers. ${ }^{38}$

Table 5: Summary statistics for the supply side estimates.

\begin{tabular}{llccccc}
\hline system type & variable & mean & p50 & $\min$ & $\max$ & $\mathrm{sd}$ \\
\hline \hline \multirow{2}{*}{ 1-product } & $m c_{0}$ & 16.81 & 17.15 & 0.03 & 46.79 & 5.79 \\
& $\partial m c / \partial q_{0}$ & 1.90 & 1.90 & 1.03 & 2.96 & 0.13 \\
\hline \multirow{3}{*}{ 2-product } & $m c_{0}$ & 13.36 & 11.44 & 0.00 & 70.42 & 9.42 \\
& $m c_{1}$ & 25.47 & 22.53 & 1.50 & 96.06 & 11.93 \\
& $\partial m c / \partial q_{0}$ & 1.79 & 1.84 & 0.07 & 2.41 & 0.25 \\
& $\partial m c / \partial q_{1}$ & 13.49 & 7.41 & 0.66 & 114.75 & 13.71 \\
\hline \multirow{3}{*}{ 3-product } & $m c_{0}$ & 12.88 & 12.16 & 0.06 & 60.46 & 8.58 \\
& $m c_{1}$ & 28.61 & 26.31 & 2.20 & 99.36 & 12.97 \\
& $m c_{2}$ & 47.80 & 45.12 & 11.46 & 119.67 & 17.43 \\
& $\partial m c / \partial q_{0}$ & 1.77 & 1.83 & 0.12 & 2.40 & 0.26 \\
& $\partial m c / \partial q_{1}$ & 4.03 & 3.64 & 0.27 & 14.31 & 1.89 \\
& $\partial m c / \partial q_{2}$ & 20.79 & 16.73 & 2.04 & 129.47 & 14.74 \\
\hline \hline
\end{tabular}

\subsection{Price and quality markups}

It is a common exercise to report the price-cost markups implied by parameter estimates in a structural econometric model of a product market. One of the contributions of this paper is to introduce the analogous concept of a quality markup that captures the extent to which the qualities chosen by firms with market power differ from those selected by a social planner.

\footnotetext{
${ }^{38}$ Due to the way we construct cost functions for multi-product cable systems there is no well-defined average because their cost-functions are piece-wise exponential as discussed in Section 5.2.
} 
Figure 4: Estimated marginal cost functions by system type

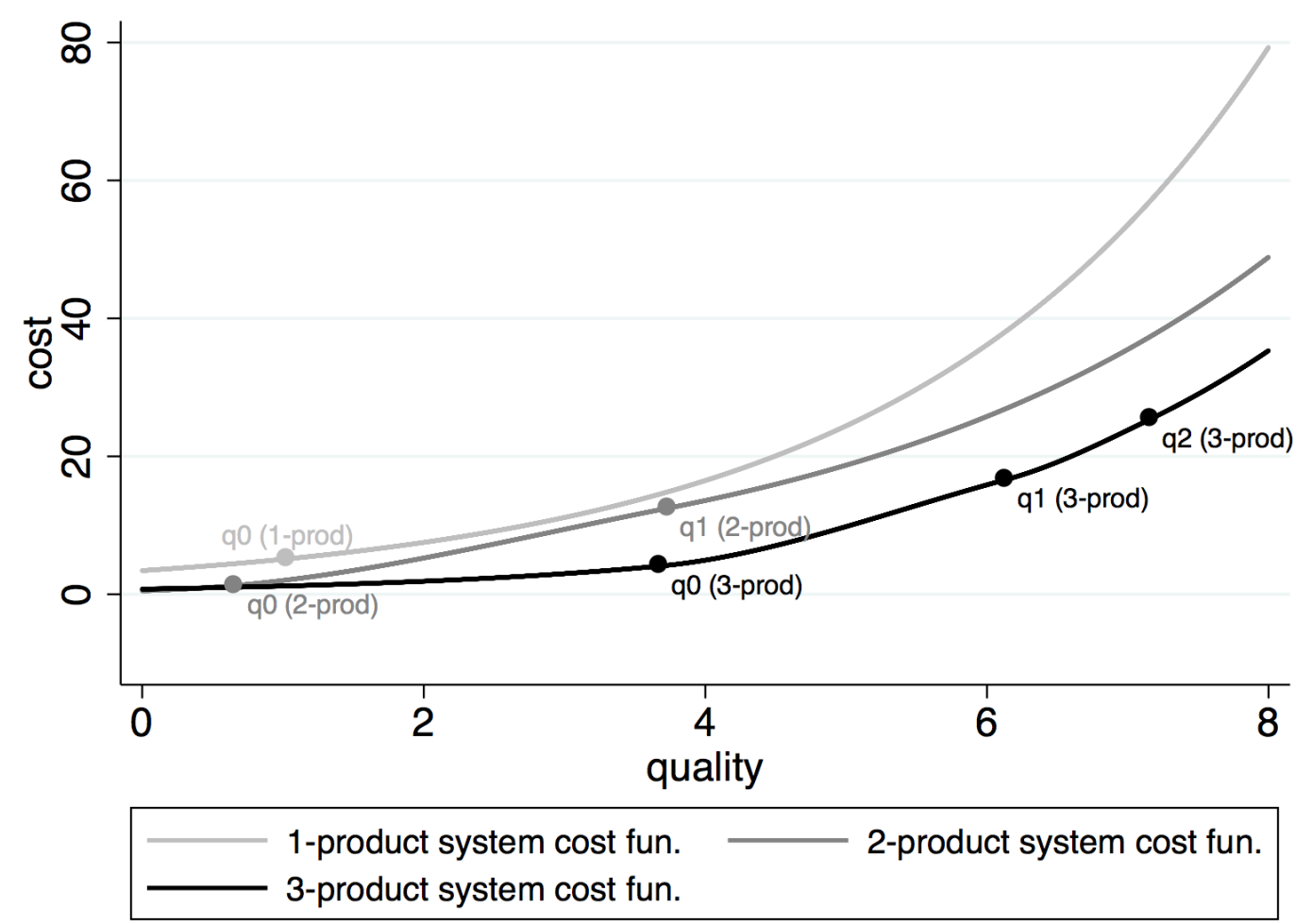

Notes:

Reported are the estimated marginal cost functions by system type (1, 2, or 3-product) and by product within each system type implied by the parameter estimates reported in Table 5. 
Table 6 reports estimated price and quality markups by market type and by product type within market implied by our baseline parameter estimates. Price markups are reported (as typical) as a percentage of that product's price, $\left(p_{j}-m c_{j}\right) / p_{j}$. These range from an estimated $17.4 \%$ for medium-quality products in 3 -good markets to $33.9 \%$ for low-quality products in 3 good markets.

Equation (7) defined a quality markup in the context of a simple single-product setting. The equivalent object in our multi-product environment is to evaluate the social planner's first-order condition for quality given in Equation (33). As for price markups, it is useful to report this markup as a percentage, and so in Table 6 we report the quality markup as a percentage of the (dollar-denominated) utility from the quality offered on that product, i.e.

$$
\text { QualityMarkup }_{j n}=\operatorname{FOC}^{S P}\left[q_{j}\right] /\left(\frac{\alpha_{q n}}{\alpha_{p n}}\right) q_{j n}
$$

where $\alpha_{q n}$ and $\alpha_{p n}$ are the average estimated quality and price sensitivity in market $n$ (distributions of which were reported in Figure 3).

Table 6: Estimated Price and Quality Markups

\begin{tabular}{l|r|rr|rr}
\hline & & \multicolumn{2}{|c|}{ Price Markups } & \multicolumn{2}{c}{ Quality Markups } \\
\hline Market Type & Obs & Mean & StdDev & Mean & StdDev \\
\hline One-product markets & 7,105 & 0.264 & 0.139 & 0.226 & 0.230 \\
\hline Two-product markets & & & & & \\
$\quad$ Low-quality products & 3,615 & 0.320 & 0.202 & 0.426 & 0.541 \\
$\quad$ High-quality products & 3,615 & 0.226 & 0.100 & 0.014 & 0.049 \\
\hline Three-product markets & & & & & \\
Low-quality products & 1,327 & 0.339 & 0.188 & 0.362 & 0.396 \\
$\quad$ Medium-quality products & 1,327 & 0.174 & 0.101 & 0.009 & 0.026 \\
$\quad$ High-quality products & 1,327 & 0.210 & 0.095 & 0.000 & 0.001 \\
\hline
\end{tabular}

Notes: Reported are estimated price and quality markups from our baseline estimation results (Table 4, Column $(2))$. Price markups are reported as a percentage of price, $\left(p_{j}-m c_{j}\right) / p_{j}$. Quality markups are reported as a percentage of the (dollar-denominated) utility from the quality offered on that product, $F O C^{S P}\left[q_{j}\right] /\left(\frac{\alpha_{q n}}{\alpha_{p n}}\right) q_{j n}$, where $F O C^{S P}\left[q_{j}\right]$ is the social planner's first-order condition for $q_{j}$, defined in equation (33) above. Estimated values are averaged across markets by market type $(1,2$, or 3 -product markets) and product type within market type.

Estimated quality markups range from zero (in which case the firm is offering the efficient quality) and $42.6 \%$ for low-quality goods in two-good markets. The largest quality markups by far are in one-good markets and for low-quality goods in two- and three-good markets. In the next subsection, we go beyond these measures of market power over price and quality at the margin to evaluate their aggregate welfare effects. 


\subsection{Counterfactual simulations}

To address the main question of this study, we need to compare observed outcomes with counterfactual ones given by a social planner. The social planner problem is to maximize total surplus, defined as the sum of consumer surplus and producer profit.

Let $\alpha_{i p}$ denote the price sensitivity of consumer type $i$, i.e., this coefficient translates utility into dollars. The expected consumer surplus $\left(C S_{i n}\right)$ for type $i$ in market $n$ is then defined as

$$
\begin{aligned}
E\left(C S_{i n}\right) & =-\frac{1}{\alpha_{i p}} E_{\epsilon}\left[\max _{j g n}\left\{u_{i j g n}\right\}\right] \\
& \left.=-\frac{1}{\alpha_{i p}} \ln \left(1+\sum_{g=c, s} \exp \left(\delta_{j g n}\left(p_{j g n}, q_{j g n}, \bar{Y}_{i n}, \xi_{g} ; \omega_{i}\right\}\right)\right)\right),
\end{aligned}
$$

where $u_{i j g n}$ is given by equation (11), and the second line follows from the distributional assumption on $\epsilon_{i g n}$. Total consumer surplus in market $n$ is then obtained by integrating over the distribution of consumer heterogeneity, i.e.,

$$
\left.E\left(C S_{n}\right)=-\int \frac{1}{\alpha_{i p}} \ln \left(1+\sum_{g=c, s} \exp \left(\delta_{j g n}\left(p_{j g n}, q_{j g n}, \bar{Y}_{i n}, \xi_{g} ; \omega_{i}\right\}\right)\right)\right) d F\left(\omega_{i}\right) .
$$

Accordingly, the first-order conditions for the social planner are:

$$
\begin{aligned}
& \text { F.O.C. }{ }^{S P}\left[p_{j c n}\right]: \frac{\partial \Pi(\cdot)}{\partial p_{j c n}}+\frac{\partial E\left(C S_{n}\right)}{\partial p_{j c n}}=0, \\
& \text { F.O.C. }{ }^{S P}\left[q_{j c n}\right]: \frac{\partial \Pi(\cdot)}{\partial q_{j c n}}+\frac{\partial E\left(C S_{n}\right)}{\partial q_{j c n}}=0,
\end{aligned}
$$

where $\frac{\partial \Pi(\cdot)}{\partial p_{j c n}}$ and $\frac{\partial \Pi(\cdot)}{\partial q_{j c n}}$ were given earlier by the left-hand-sides of equations (20) and (21) respectively.

Here we present counterfactual experiments where we calculate the optimal social planner's quality and price using (32) and (33), given our estimates of consumer preferences and operator cost functions described in the previous section. The results from our experiments are summarized in Table 7.

First, reported in Column A of Table 7, we compute the socially optimal quality levels at the observed prices and evaluate the corresponding changes in qualities and consumer, producer, and total welfare. This includes our summary measure of Market Power over Quality (MPQ), defined in Equation (8) as the change in total surplus between observed prices and qualities and observed prices and the social planner's qualities.

Second, reported in Column B of Table 7, we compute the socially optimal prices at the 
quality levels from the first step and evaluate the corresponding changes in prices and welfare. ${ }^{39}$ This includes our summary measure of Market Power over Price (MPP), defined in Equation (9) as the change in total surplus between observed prices and the social planner's qualities and the social planner's prices and qualities. Finally, reported in Column $\mathrm{C}$ of Table 7, we compute the socially optimal prices and qualities and evaluate the corresponding changes in prices, qualities, and welfare.

Turning first to the effects of market power over quality in Column A, we find, at the observed prices, monopoly cable operators under-provide (or degrade) quality: low-quality products are predicted to increase by $55 \%$, while medium- and high-quality products by $7 \%$. Consumers surplus increases by an estimated $43 \%$, firm profits fall by an estimated $33 \%$, and total surplus increases by an estimated 10\%. Consistent with the theory results in Mussa and Rosen (1978) and the empirical results in Crawford and Shum (2007)) using a similar dataset, with fixed prices, we see evidence of nearly-efficient qualities being offered for medium- and high-quality products, but significant quality degradation for low-quality products.

In the second and third counterfactuals, we allow the social planner to also choose quality. In the second counterfactual, in Column B, we compare these outcomes with the efficient qualities at the observed prices. The results indicate that market power over price is also important. Prices fall between an estimated $33 \%$ and $74 \%$, consumer surplus rises by an estimated $54 \%$, profits fall (to nothing), and total surplus increases by $7 \%$.

Column $\mathrm{C}$ contains the most interesting patterns. We see that, compared to the first counterfactual which only allows the social planner to choose qualities optimally while holding prices fixed at monopolist's levels (which implied a tendency for the monopolist to degrade quality), the results from the third counterfactual show that, once we allow the social planner to jointly set prices and qualities, he would set quality levels to be lower than the monopolists' choices, the opposite of quality degradation. On average, socially optimal qualities would be lower by between $23 \%$ and $55 \%$ compared to observed values (and by between $45 \%$ and $58 \%$ compared to the social planner's qualities at observed prices in Column A). Consumer surplus more than doubles - an effect far greater than the effect of efficient qualities or prices on their own - and total surplus increases by an estimated $17 \%$.

The classic results from Mussa and Rosen (1978) predict only quality degradation. Evidently, our estimated preferences - which are outside the class of uni-dimensional quasilinear preferences considered in Mussa and Rosen (1978) and Crawford and Shum (2007) - imply that consumers are quite willing to trade off lower quality for lower prices, leading to both price and quality inflation under monopoly. Such results are new and surprising relative to the literature.

In the last two rows of table 7 , we decompose the total welfare effects into components arising from market power over price and market power over quality, as defined in Eqs. (8) and (9).

\footnotetext{
${ }^{39}$ These efficient prices are just the marginal costs evaluated at the qualities in Column A.
} 
Table 7: Welfare effects of market power over quality (and price)

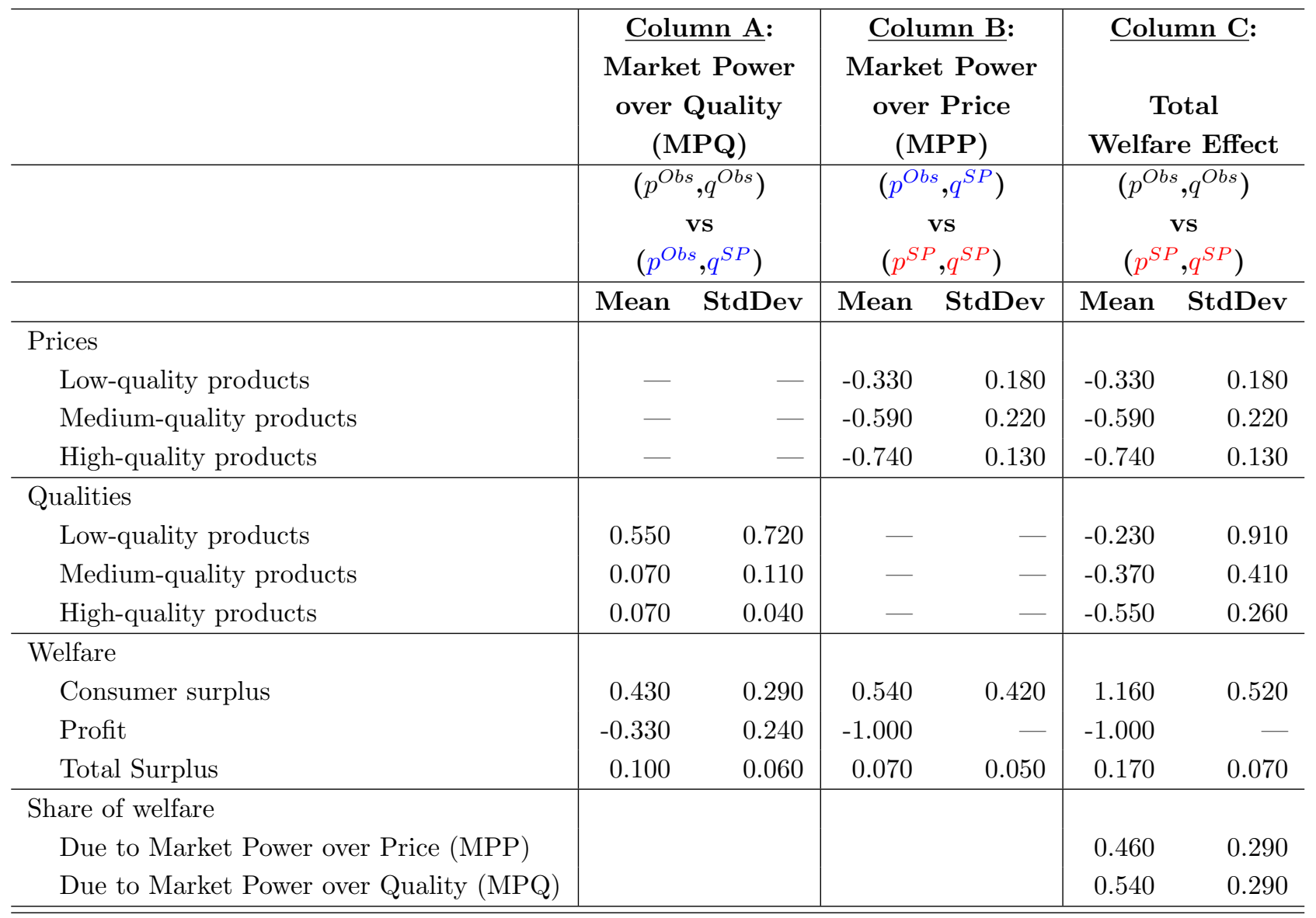


In this table, we normalize each of the numbers by dividing by the overall change in the total welfare, i.e., by $T S^{*}$ in Eq. (10), so that each variable is between 0 and 1 and can be interpreted as a percentage of the total welfare change. We see that each is of roughly equal importance: market power over price accounts for $46 \%$ of the total welfare change while market power over quality accounts for $54 \%{ }^{40}$ These findings suggest that distorting prices away from marginal cost are more profitable for a monopolist who oversees an entire product line, rather than only a single product. ${ }^{41}$ Figure 5 presents the information from the last two rows of table 7 in histogram form, and illustrates the significant heterogeneity across markets in the distributions of $M P P^{*}$ and $M P Q^{*}$.

Figure 5: Histograms for $M P P^{*}$ and $M P Q^{*}$

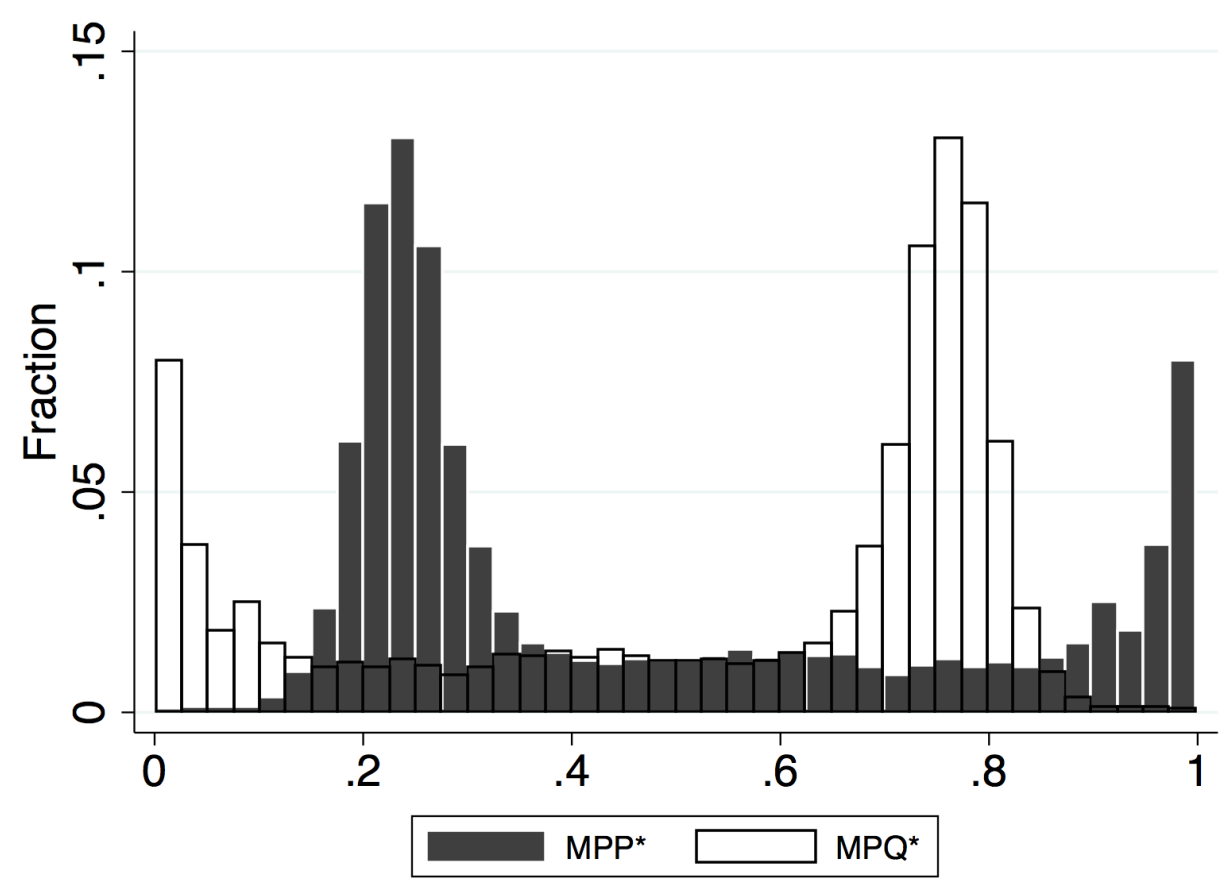

\section{Conclusions}

In this paper, we develop a model of consumer and producer behavior to measure the welfare consequences of endogenous quality choice in imperfectly competitive markets for paid televi-

\footnotetext{
${ }^{40}$ There are also interesting patterns across the different market types. In one-good markets, the market power over quality component is much more prominent (making up $74 \%$ of the total welfare change), while market power over price is more prominent in two- and three-good markets (making up, respectively, $81 \%$ and $60 \%$ of the welfare change).

${ }^{41}$ However, a more conclusive explanation here requires delving into the monopolist's choice of how many products to offer, a complicated problem which we leave for future work.
} 
sion services. We introduce the concept of a "quality markup" analogous to the familiar price markup to measure the deviation between private and efficient quality choice and measure quality markups for cable television services. We also quantify the welfare effects of market power over quality and compare its importance relative to the familiar effects of market power over prices.

We estimate demand- and supply-side structural parameters using data from the U.S. local cable markets in 1997-2006. Our estimation results reveal considerable variation in consumer preferences across markets. The estimates of cost functions suggest substantial heterogeneity in technologies used by the cable firms.

Our results imply that average price-cost margins range between 17 and 34 percent and average quality margins range between 0 and $43 \%$, with substantially higher markups set for low-quality products. To determine the welfare effects of market power over quality, we simulated several counterfactual scenarios where a social planner chooses price, quality, or both. Keeping prices fixed at observed levels, offered qualities are too low, by between 7 and $55 \%$, confirming previous results that found evidence of quality degradation in cable markets. Allowing for both efficient prices and qualities flips this conclusion, however, and results in estimates that both are too high: qualities between $23 \%$ and $55 \%$ and prices between $33 \%$ and $74 \%$. Furthermore, we find that market power over price accounts for (only) $46 \%$ of the total welfare effects of endogenous prices and qualities. These are potentially important insights into how consumers trade off price versus quality and may be particularly relevant to US policymakers concerned about high and rising pay television prices.

These results point the way to possible extensions. Based on features of the institutional environment, we take the number of products offered by firms as fixed. We assume consumers have preferences over a scalar "quality" variable, whereas other work in the industry focuses on heterogeneous tastes across multiple different television networks. Integrating that approach with ours would be useful. Our analysis is static, and long-run investments in quality are likely made in a dynamic environment. This is particularly relevant as we focus only on television services, whereas contemporary communications distributors provide television along with telephone and broadband internet access services, the qualities of which are also important and factors in long-run investment decisions. Finally, we focus on the quality (and price) choices of downstream distributors, taking as given the qualities of upstream television networks; generalizing the analysis to those firms' quality choices would also be of interest. 


\section{References}

Ackerberg, D., Caves, K., and Frazer, G. (2006). Structural identification of production functions. Working paper.

Ackerberg, D., Crawford, G., and Hahn, J. (2011). Orthogonal instruments: Estimating price elasticities in the presence of endogenous product characteristics. Working paper. University of Warwick.

Berry, S. (1994). Estimating discrete-choice models of product differentiation. RAND Journal of Economics, 25:242-262.

Berry, S., Levinsohn, J., and Pakes, A. (1995). Automobile prices in market equilibrium. Econometrica, 63:841-890.

Berry, S. and Pakes, A. (1993). Some applications and limitations of recent advances in empirical industrial organization: Merger analysis. American Economic Review, 83(2):247-252.

Berry, S. T. and Waldfogel, J. (2001). Do mergers increase product variety? evidence from radio broadcasting. The Quarterly Journal of Economics, 116(3):1009-1025.

Byrne, D. P. (2011). Consolidation and price discrimination in the cable television industry. Working Paper, University of Melbourne.

Chu, C. S. (2007). The effect of satellite entry on product quality for cable. Unpublished dissertation, Stanford University.

Chu, C. S. (2010). The effect of satellite entry on cable television prices and product quality. The RAND Journal of Economics, 41(4):730-764.

Clerides, S. K. (2002). Book value: intertemporal pricing and quality discrimination in the U.S. market for books. International Journal of Industrial Organization, 20(10):1385-1408.

Crawford, G. S. (2000). The impact of the 1992 cable act on household demand and welfare. RAND Journal of Economics, 31:442-449.

Crawford, G. S. (2008). The discriminatory incentives to bundle in the cable television industry. Quantitative Marketing and Economics, 6(1):41-78.

Crawford, G. S. (2012). Endogenous product choice: A progress report. International Journal of Industrial Organization, 30(3):315-320.

Crawford, G. S., Lee, R., Whinston, M., and Yurukoglu, A. (2015). The welfare effects of vertical integration in multichannel television markets. Unpublished manuscript, Stanford University. 
Crawford, G. S. and Shum, M. (2007). Monopoly quality degradation and regulation in cable television. Journal of Law and Economics, 50:181-219.

Crawford, G. S. and Yurukoglu, A. (2012). The welfare effects of bundling in multichannel television markets. American Economic Review, 102(2):643-685.

DOJ and FTC (2010). Horizontal merger guidelines. Technical report, U.S. Department of Justice and the Federal Trade Commission.

Draganska, M., Mazzeo, M., and Seim, K. (2009). Beyond plain vanilla: Modeling joint product assortment and pricing decisions. Quantitative Marketing and Economics, 7(2):105-146.

Eizenberg, A. (2014). Upstream innovation and product variety in the u.s. home pc market. Review of Economic Studies, 81:1003-1045.

Elhauge, E. (2011). United States Antitrust Law and Economics. Foundation Press, 2 edition.

Fan, Y. (2013). Ownership consolidation and product characteristics: A study of the U.S. daily newspaper market. American Economic Review, 105:1598-1628.

FCC (2000). Fact sheet. Cable television infromation bulletin. Federal Communications Commission, 445 12th Street, S.W., Washington, D.C. http://www.fcc.gov/mb/facts/csgen.html (accessed March 01, 2009).

Gandhi, A., Froeb, L., Tschantz, S., and Werden, G. J. (2008). Post-merger product repositioning. Journal of Industrial Economics, 56(1):49-67.

Goolsbee, A. and Petrin, A. (2004). The consumer gains from Direct Broadcast Satellites and the competition with cable TV. Econometrica, 72:351-381.

Hazlett, T. and Spitzer, M. (1997). Public Policy toward Cable Television. The Economics of Rate Controls. The MIT Press, Cambridge, Massachusetts, and The AEI Press, Washington, D.C.

Maskin, E. and Riley, J. (1984). Monopoly with incomplete information. The RAND Journal of Economics, 15(2):171-196.

McManus, B. (2007). Nonlinear pricing in an oligopoly market: The case of specialty coffee. The Rand Journal of Economics, 38(2):512-532.

Mussa, M. and Rosen, S. (1978). Monopoly and product quality. Journal of Economic Theory, 18(2):301-317.

Nevo, A. (2001). Measuring market power in the ready-to-eat cereal industry. Econometrica, $69(2): 307-342$. 
Nosko, C. (2014). Competition and quality choice in the cpu market. Working Paper, University of Chicago, Graduate School of Business.

Olley, S. and Pakes, A. (1996). The dynamics of productivity in the telecommunications equipment industry. Econometrica, 64(6):1263-1297.

Petrin, A. (2002). Quantifying the benefits of new products: The case of the minivan. The Journal of Political Economy, 110(4):705-729.

Rochet, J.-C. and Stole, L. A. (2002). Nonlinear pricing with random participation. Review of Economic Studies, 69(1):277-311.

Shcherbakov, O. (2012). Measuring consumer switching costs in the television industry. University of Mannheim, Unpublished Manuscript.

Spence, M. (1975). Monopoly, quality, and regulation. The Bell Journal of Economics, 6(2):417429.

Sweeting, A. (2010). The effects of mergers on product positioning: evidence from the music radio industry. The Rand Journal of Economics, 41(2):372-397.

Sweeting, A. (2013). Dynamic product positioning in differentiated product markets: the effects of fees for musical performance rights on the commercial radio industry. Econometrica, 81(5):1763-1803.

Verboven, F. (2002). Quality-based price discrimination and tax incidence: Evidence from gasoline and diesel cars. The RAND Journal of Economics, 33(2):275-297. 


\section{A Alternative specifications}

Table 8 reports parameter estimates for two alternative specifications (both GMM second stage). The first one is "OLS-type" where price and quality variables were not instrumented using the cost shifters. To obtain estimates for the second specification, "min-IV", we used minimum set of instrumental variables (only ownership-based instruments were employed). OLS-type specification results in lower price coefficients as one would expect in a linear model. Estimation results from the "min-IV" specification turn out to be quite similar to the ones reported in the main text.

Table 8: Results for alternative specifications, 1997-2006 (No. obs 12,214).

\begin{tabular}{lcccc}
\hline \multirow{2}{*}{ parameter } & \multicolumn{2}{c}{ OLS-type } & \multicolumn{2}{c}{ min-IV } \\
\cline { 2 - 5 } & coef. & s.e. & coef. & s.e. \\
\hline \hline price coefficient, $\alpha_{i p}$ & & & & \\
\hline mean & -0.553 & $(0.000)$ & -0.684 & $(0.011)$ \\
income & -0.304 & $(0.027)$ & -0.433 & $(0.022)$ \\
h-size & 0.190 & $(0.017)$ & 0.415 & $(0.054)$ \\
urban & -0.161 & $(0.029)$ & -0.184 & $(0.036)$ \\
sigma & 0.100 & $(0.003)$ & 0.119 & $(0.011)$ \\
\hline quality coefficient, $\alpha_{i q}$ & & & & \\
\hline mean & 1.105 & $(0.041)$ & 1.228 & $(0.092)$ \\
income & -0.265 & $(0.265)$ & -0.336 & $(0.807)$ \\
h-size & 0.459 & $(0.200)$ & 0.227 & $(0.387)$ \\
urban & -0.003 & $(0.276)$ & 0.334 & $(0.888)$ \\
sigma & 0.352 & $(0.003)$ & 0.268 & $(0.011)$ \\
\hline corr $\left(a_{i p}, a_{i q}\right)$ & -0.669 & $(0.010)$ & -0.451 & $(0.013)$ \\
\hline demand t-dummies & Yes & & Yes & \\
supply t-dummies & Yes & & Yes & \\
\hline \hline
\end{tabular}

Note: full estimation results are available from the authors upon request. 


\section{B Price elasticities}

Figure 6: Histogram for price and quality sensitivity across markets
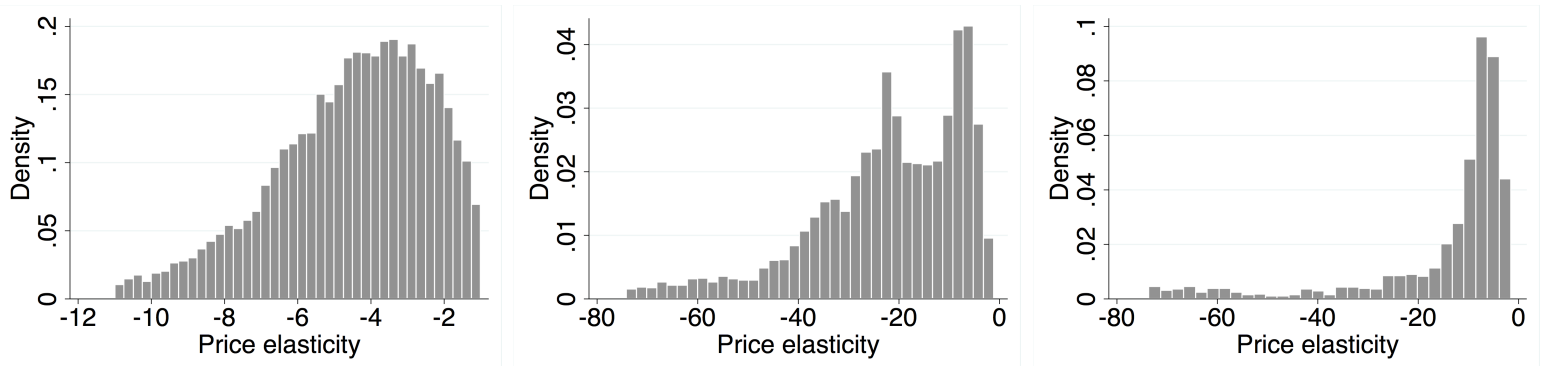

Table 9: Summary statistics for own price elasticity by product type across markets

\begin{tabular}{lrrrrr}
\hline variable & mean & $\mathrm{p} 50$ & $\min$ & $\max$ & $\mathrm{sd}$ \\
\hline low $q$ & -4.511 & -4.226 & -10.987 & -1.004 & 2.124 \\
medium $q$ & -22.091 & -20.269 & -74.159 & -1.146 & 15.051 \\
high $q$ & -14.560 & -8.137 & -73.594 & -1.524 & 16.065 \\
\hline
\end{tabular}

Note: $5 \%$ outliers are excluded 


\section{Full estimation results}

Table 10: Estimation results, 1997-2006 (No. obs 12,214).

\begin{tabular}{|c|c|c|c|c|}
\hline \multirow{2}{*}{ parameter } & \multicolumn{2}{|c|}{ (1) } & \multicolumn{2}{|c|}{$(2)$} \\
\hline & coef. & s.e. & coef. & s.e. \\
\hline \multicolumn{5}{|c|}{ price coefficient, $\alpha_{i p}$} \\
\hline mean & -0.673 & $(0.001)$ & -0.682 & $(0.023)$ \\
\hline income & & & -0.418 & $(0.091)$ \\
\hline h-size & & & 0.396 & $(0.062)$ \\
\hline urban & & & -0.173 & $(0.017)$ \\
\hline sigma & 0.102 & $(0.006)$ & 0.122 & $(0.013)$ \\
\hline \multicolumn{5}{|c|}{ quality coefficient, $\alpha_{i q}$} \\
\hline mean & 1.108 & $(0.032)$ & 1.225 & $(0.083)$ \\
\hline income & & & -0.337 & $(0.413)$ \\
\hline h-size & & & 0.221 & $(0.144)$ \\
\hline urban & & & 0.331 & $(0.184)$ \\
\hline sigma & 0.310 & $(0.007)$ & 0.266 & $(0.007)$ \\
\hline $\operatorname{corr}\left(a_{i p}, a_{i q}\right)$ & -0.545 & $(0.032)$ & -0.481 & $(0.090)$ \\
\hline \multicolumn{5}{|c|}{ demand cab t-dummies } \\
\hline const & 10.313 & $(0.085)$ & 10.218 & $(0.283)$ \\
\hline y-1998 & 0.650 & $(0.109)$ & 0.590 & $(0.116)$ \\
\hline y-1999 & 2.022 & $(0.113)$ & 1.879 & $(0.133)$ \\
\hline$y-2000$ & 1.961 & $(0.128)$ & 1.815 & $(0.146)$ \\
\hline$y-2001$ & 1.607 & $(0.149)$ & 1.415 & $(0.162)$ \\
\hline$y-2002$ & -0.294 & $(0.160)$ & -0.415 & $(0.192)$ \\
\hline$y-2003$ & 1.976 & $(0.229)$ & 2.038 & $(0.244)$ \\
\hline$y-2004$ & 2.596 & $(0.290)$ & 2.631 & $(0.336)$ \\
\hline$y-2005$ & 0.243 & $(0.558)$ & 0.040 & $(0.583)$ \\
\hline$y-2006$ & 1.165 & $(0.272)$ & 1.002 & $(0.333)$ \\
\hline \multicolumn{5}{|c|}{ demand sat $t$-dummies } \\
\hline const & 5.994 & $(0.056)$ & 5.915 & $(0.236)$ \\
\hline y-1998 & 0.351 & $(0.023)$ & 0.339 & $(0.029)$ \\
\hline y-1999 & 1.072 & $(0.025)$ & 1.062 & $(0.049)$ \\
\hline$y-2000$ & 0.016 & $(0.134)$ & -0.581 & $(0.267)$ \\
\hline$y-2001$ & 0.273 & $(0.125)$ & -0.354 & $(0.251)$ \\
\hline$y-2002$ & 2.698 & $(0.211)$ & 1.773 & $(0.387)$ \\
\hline$y-2003$ & 9.980 & $3(9.213)$ & 9.172 & $(0.422)$ \\
\hline$y-2004$ & 7.866 & $(0.258)$ & 6.935 & $(0.494)$ \\
\hline$y-2005$ & 7.043 & $(0.303)$ & 5.690 & $(0.549)$ \\
\hline$y-2006$ & 6.364 & $(0.290)$ & 5.101 & $(0.570)$ \\
\hline
\end{tabular}




\section{C (cont.) Full estimation results}

Table 11: Estimation results, 1997-2006 (No. obs 12,214).

\begin{tabular}{|c|c|c|c|c|}
\hline \multirow{2}{*}{ parameter } & \multicolumn{2}{|c|}{ (1) } & \multicolumn{2}{|c|}{ (2) } \\
\hline & coef. & s.e. & coef. & s.e. \\
\hline \multicolumn{5}{|c|}{ supply parameters, $c_{0 j}$} \\
\hline const & 1.779 & $(0.395)$ & 0.960 & $(0.546)$ \\
\hline$y-1998$ & 0.017 & $(0.074)$ & -0.132 & $(0.316)$ \\
\hline$y-1999$ & -0.313 & $(0.387)$ & -0.049 & $(0.103)$ \\
\hline$y-2000$ & 0.051 & $(0.103)$ & 0.071 & $(0.070)$ \\
\hline$y-2001$ & 0.131 & $(0.104)$ & 0.109 & $(0.076)$ \\
\hline$y-2002$ & -1.952 & $(1.347)$ & -0.917 & $(0.573)$ \\
\hline$y-2003$ & -0.535 & $(0.248)$ & -0.575 & $(0.172)$ \\
\hline$y-2004$ & 0.078 & $(0.204)$ & 0.089 & $(0.237)$ \\
\hline$y-2005$ & -0.219 & $(0.401)$ & -0.158 & $(0.409)$ \\
\hline$y-2006$ & -0.204 & $(0.240)$ & -0.110 & $(0.200)$ \\
\hline $\operatorname{MSO}\left(p_{0}\right)$ & 0.448 & $(0.157)$ & 0.568 & $(0.122)$ \\
\hline $\operatorname{MSO}\left(p_{1}\right)$ & -0.696 & $(0.217)$ & -0.648 & $(0.123)$ \\
\hline $\operatorname{MSO}\left(p_{2}\right)$ & 0.454 & $(0.212)$ & 0.195 & $(0.093)$ \\
\hline $\operatorname{MSO}\left(q_{0}\right)$ & -0.651 & $(1.742)$ & 0.245 & $(1.425)$ \\
\hline $\operatorname{MSO}\left(q_{1}\right)$ & 0.717 & $(0.913)$ & 0.146 & $(1.031)$ \\
\hline $\operatorname{MSO}\left(q_{2}\right)$ & -2.528 & $(2.348)$ & 0.147 & $(1.891)$ \\
\hline MSO sub. & 0.000 & $(0.000)$ & 0.000 & $(0.000)$ \\
\hline MSO cap. & 0.011 & $(0.009)$ & 0.015 & $(0.006)$ \\
\hline MSO num. prod. & -0.304 & $(0.138)$ & -0.234 & $(0.223)$ \\
\hline Own cap. & -0.002 & $(0.005)$ & 0.000 & $(0.003)$ \\
\hline Own m.coax. & -0.031 & $(0.101)$ & -0.017 & $(0.058)$ \\
\hline \multicolumn{5}{|c|}{ supply parameters, $c_{1 j}$} \\
\hline const & 0.370 & $(0.317)$ & 0.523 & $(0.262)$ \\
\hline$y-1998$ & -0.044 & $(0.077)$ & 0.042 & $(0.096)$ \\
\hline y-1999 & 0.040 & $(0.076)$ & 0.011 & $(0.042)$ \\
\hline$y-2000$ & -0.015 & $(0.057)$ & -0.022 & $(0.021)$ \\
\hline$y-2001$ & -0.041 & $(0.033)$ & -0.032 & $(0.022)$ \\
\hline$y-2002$ & 1.085 & $(0.733)$ & 0.139 & $(0.173)$ \\
\hline$y-2003$ & 0.214 & $(0.197)$ & 0.103 & $(0.040)$ \\
\hline$y-2004$ & 0.100 & $(0.180)$ & -0.035 & $(0.076)$ \\
\hline$y-2005$ & 0.137 & $(0.286)$ & -0.013 & $(0.091)$ \\
\hline$y-2006$ & 0.048 & $(0.179)$ & -0.055 & $(0.062)$ \\
\hline $\operatorname{MSO}\left(p_{0}\right)$ & 0.098 & $(0.267)$ & -0.082 & $(0.044)$ \\
\hline $\operatorname{MSO}\left(p_{1}\right)$ & 0.286 & $(0.078)$ & 0.195 & $(0.015)$ \\
\hline $\operatorname{MSO}\left(p_{2}\right)$ & -0.212 & $(0.120)$ & -0.026 & $(0.028)$ \\
\hline $\operatorname{MSO}\left(q_{0}\right)$ & -1.339 & $(2.802)$ & -0.429 & $(0.649)$ \\
\hline $\operatorname{MSO}\left(q_{1}\right)$ & -0.365 & $(0.405)$ & 0.049 & $(0.277)$ \\
\hline $\operatorname{MSO}\left(q_{2}\right)$ & 1.674 & $(0.977)$ & 0.016 & $(0.454)$ \\
\hline MSO sub. & -0.000 & $(0.000)$ & -0.000 & $(0.000)$ \\
\hline MSO cap. & -0.003 & $40_{(0.004)}$ & -0.003 & $(0.002)$ \\
\hline MSO num. prod. & -0.059 & $(0.126)$ & 0.006 & $(0.058)$ \\
\hline Own cap. & 0.000 & $(0.003)$ & -0.001 & $(0.001)$ \\
\hline Own m.coax. & 0.017 & $(0.072)$ & -0.001 & $(0.019)$ \\
\hline
\end{tabular}

